IZA DP No. 7316

The Impact of Internet Diffusion on Marriage Rates:

Evidence from the Broadband Market

Andriana Bellou

March 2013 


\title{
The Impact of Internet Diffusion on Marriage Rates: Evidence from the Broadband Market
}

\author{
Andriana Bellou \\ Université de Montréal, \\ CIREQ, CIRANO \& IZA \\ Discussion Paper No. 7316 \\ March 2013 \\ IZA \\ P.O. Box 7240 \\ 53072 Bonn \\ Germany \\ Phone: +49-228-3894-0 \\ Fax: +49-228-3894-180 \\ E-mail: iza@iza.org
}

Any opinions expressed here are those of the author(s) and not those of IZA. Research published in this series may include views on policy, but the institute itself takes no institutional policy positions. The IZA research network is committed to the IZA Guiding Principles of Research Integrity.

The Institute for the Study of Labor (IZA) in Bonn is a local and virtual international research center and a place of communication between science, politics and business. IZA is an independent nonprofit organization supported by Deutsche Post Foundation. The center is associated with the University of Bonn and offers a stimulating research environment through its international network, workshops and conferences, data service, project support, research visits and doctoral program. IZA engages in (i) original and internationally competitive research in all fields of labor economics, (ii) development of policy concepts, and (iii) dissemination of research results and concepts to the interested public.

IZA Discussion Papers often represent preliminary work and are circulated to encourage discussion. Citation of such a paper should account for its provisional character. A revised version may be available directly from the author. 
IZA Discussion Paper No. 7316

March 2013

\section{ABSTRACT \\ The Impact of Internet Diffusion on Marriage Rates: Evidence from the Broadband Market ${ }^{*}$}

The Internet has the potential to reduce search frictions by allowing individuals to identify faster a larger set of available options that conform to their preferences. One market that stands to benefit from this process is that of marriage. This paper empirically examines the implications of Internet diffusion in the United States since the 1990s on one aspect of this market: marriage rates. Exploring sharp temporal and geographic variation in the pattern of consumer broadband adoption, I find that the latter has significantly contributed to increased marriages rates among 21-30 year olds. A number of tests suggest that this relationship is causal and that it varies across demographic groups potentially facing thinner marriage markets. I also provide some suggestive evidence that Internet has likely crowded out other traditional meeting venues, such as through family and friends.

JEL Classification: J11, J12, D12, R11, O33

Keywords: internet, broadband, marriage, search

Corresponding author:

Andriana Bellou

Université de Montréal

Département de Sciences Économiques

C.P. 6128 succursale Centre-ville

Montréal, H3C $3 J 7$

Canada

E-mail: andriana.bellou@umontreal.ca

\footnotetext{
* I would like to thank Rachana Bhatt and seminar participants at the University of Montreal and the 2010 CEA meeting for their helpful comments. Funding from the Alexander Onassis Foundation is gratefully acknowledged.
} 


\section{Introduction}

The last 15 years have witnessed a dramatic explosion in the growth of the Internet. The first wave of this technology - dial-up - was widely introduced in the United States in the early 1990s, whereas the second - broadband - began to diffuse after the 1996 Telecommunications Act. ${ }^{1}$ This second wave has arguably been more influential for the evolution of daily communications, activities and transactions (NTIA 2004, 2010). The online environment has become a close alternative to traditional offline markets, with the additional potential advantage of efficiency. It enables access to a virtual space that supplies consumers with an abundance of product-specific options in a short amount of time. Given that in a traditional offline setting search is often impeded by the substantial difficulty to identify all the available alternatives, the Internet is thought to offer a centralized solution to this problem thereby reducing search frictions.

Two markets that are characterized by such frictions, and therefore stand to benefit from the growing presence of the Internet, are those of labor and marriage. To date, a number of studies have documented the active role of the Internet in the worker-firm matching process. ${ }^{2}$ The market for romantic partners functions in ways similar to the labor market. Individuals are in search of a partner, there is difficulty to identify potentially suitable mates, uncertainty regarding match quality, an optimal stopping rule for search and turnover. While economists have acknowledged the theoretical potential of the Internet to affect search and matching in the

\footnotetext{
1 This was the first major amendment of the United States telecommunications law since the Communications Act of 1934. Among the primary goals of the 1996 Act was the deregulation of the broadcasting market and the promotion of competition in the telecommunications industry by encouraging the entry of any communications business in the market. It was also the first time that the "Internet" was included in broadcasting and spectrum allotment.

${ }^{2}$ Labor market outcomes that have been considered are unemployment duration, employer-to-employer flows, job search behavior, the racial unemployment gap and the quality of employment matches. See Kuhn and Skuterund (2004), Fountain (2005), Stevenson (2006, 2009), Hadass (2004), Bellou (2010). For other outcomes also see Brown and Goolsbee (2002), Liebowitz and Zentner (2010) and Goolsbee and Guryan (2006), Kroft and Pope (2012).
} 
marriage market as well, little progress has been made due to data limitations (Stevenson and Wolfers (2007), Hitsch et al. (2010)). This paper aims to fill this gap by testing whether the diffusion of this technology has had a measurable impact on one of the aspects of the marital search process: the transition into first marriage. To my knowledge, this is the first paper to empirically address this link.

A preliminary glance in the data suggests that an association between flows into marriage and Internet diffusion exists and is striking. According to Rosenfeld and Thomas (2012), this technology is the second most popular venue of meeting a partner after traditional offline social networking, especially among young people. Among couples that met in 1994-1998, 3.9\% report having met online for the first time. Interestingly, this number has risen to $11 \%$ and $20 \%$ for couples that met between 1999-2003 and 2004-2006 respectively. ${ }^{3}$ This is unsurprising given that the last two periods also coincide with the beginning of an era of dramatic growth in high-speed and broadband Internet technologies that has profoundly transformed the social environment.

To offer more rigorous evidence on the link between the Internet and marriage rates, I exploit the sharp geographic (state) and temporal variation in the pattern of home broadband adoption between 1990 and 2005. Conditioning on a number of individual and state, time-varying characteristics in a setting with state, year fixed effects and state-specific trends, I find that expansions in Internet availability are associated with significant increases in the marriage rates in the benchmark 21-30 years old white population. The effect is also sizeable and significant for African Americans, a minority group potentially facing a relatively thinner marriage market.

\footnotetext{
${ }^{3}$ Rosenfeld and Thomas (2012) conduct a descriptive sociological analysis of the ways the Internet has changed the market for romantic partners in the U.S. His analysis is based on data from the "How Couples Meet and Stay Together" survey (HCMST). It is a nationally representative survey of 4000 adults of whom almost $80 \%$ are romantically linked to a spouse. Non-traditional, same-sex couples are oversampled. For a similar study covering Australia, the United Kingdom and the United States see Dutton et al. (2008).
} 
Quantitatively, the estimates suggest that the realized increase in broadband penetration throughout this period has contributed to higher marriage rates in the benchmark population by roughly $13 \%-30 \%$ relative to what they might have been in the absence of this technology. A series of falsification tests based on the particular timing of the advent of broadband, as well as an instrumental variables strategy provide strong suggestive evidence in favor of the causal interpretation of this result.

Whereas the analysis focuses on the transition into first marriage, the Internet may have been a powerful force in shaping other marital decisions as well. For instance, if marriages initiated through the Internet are of higher quality, they will likely be more durable. Consequently, the incidence of divorce and remarriage may decrease. While the CPS does not provide information to study these outcomes appropriately, I use the available data to evaluate whether the Internet has impacted on the propensity of the ever-married population to be in a formal relationship at all times. I find that that such an effect exists and is positive, namely that Internet expansion is associated with higher propensity to remain married as opposed to be separated/divorced. However, it is not possible to distinguish whether this is due to first marriages being more durable or to remarriage being facilitated by the presence of the Internet.

While the empirical analysis largely focuses on establishing whether this technology can improve matching efficiency, plausible mechanisms underlying this potential relationship are also discussed. In particular, I show that online dating usage is associated with increases in marriage rates and I discuss suggestive evidence that the Internet has played a displacing rather than complementary role in the social arena, likely crowding out other traditional forms of search such as through friends and family. Furthermore, it appears that the presence of the Internet has had a negative impact on social capital accumulation, as it has significantly reduced the time young people spend on socializing and physically communicating. 
This work complements related research by Hitsch et al. (2010), which relies on data from an online dating service to infer revealed mate preferences. One key finding is that the match outcomes in the online dating market appear to be approximately efficient in the sense that they are the outcomes that would arise in an environment with no search frictions. Nevertheless, because of data restrictions, the authors cannot address whether online meetings result in offline partnerships and subsequently to marriage. This is one direction where this paper contributes.

This research makes two other important contributions. First, it relates to the literature on the determinants of the timing of the first marriage. This is a particularly crucial decision for women since it is critically tied to human capital accumulation and career considerations. ${ }^{4}$ Moreover, it is worth highlighting that, whereas the median age at first marriage rose precipitously throughout the 1970s and 1980s, these trends interestingly began to level-off in the mid-to-late 1990s, exactly when advanced Internet services emerged. ${ }^{5}$ While these trends cannot be viewed in isolation from the relative strength of other factors affecting fertility timing or educational and occupational opportunities, it is still interesting to identify whether recent technological advancements, such as the Internet, can partly account for the post-1990 acceleration in marriage rates among 21-30 year olds.

Finally, these findings complement recent, policy-relevant research on the economic implications of broadband, a technology whose benefits will still take time to be fully revealed. Since its advent, a wide range of policies subsidizing Internet infrastructure have arisen and resources are devoted to promote universal deployment. Studies that sought to evaluate such

\footnotetext{
${ }^{4}$ There is an extensive literature linking early marriage for women to lower educational achievement and poverty (Klepinger et al. (1995), Dahl (2005)) and early fertility to lower labor market earnings (Blackburn et al. (1993), Loughran et al (2009)). Goldin and Katz (2002) and Bailey (2006) also discuss how another technological phenomenon, oral contraception, affected labor force participation and the occupational choices of women in the 1970s via increases in the age at first marriage and age at first birth.

${ }^{5}$ Median age at first marriage for women (men) was 23.9 (26.1) in 1990, 24.5 (26.9) in 1995, 25.1 (26.8) in 2000 and 25.3 (27.1) in 2005 (Census Estimates).
} 
benefits have predicted faster economic growth for broadband-using communities emphasizing the importance of this technology for regional development. ${ }^{6}$ Establishing that there are also indirect effects on social aspects, such as family formation, that have implications for the operation of the labor market, highlights the impact of the Internet as a technology with farreaching effects.

The remainder of the paper is organized as follows. Section 2 describes a conceptual framework to motivate the relationship between Internet diffusion and marriage flows. Section 3 presents the data, and Section 4 details the empirical strategy. Section 5 discusses the results, addresses identification concerns and presents a heterogeneity analysis of the main findings. Section 6 provides a discussion of potential underlying mechanisms, and Section 7 concludes.

\section{Conceptual Framework}

Search frictions play an important role in the functioning of labor and marriage markets and are typically studied in the context of dynamic search models. This framework, in particular, has been extensively used to model the marital search process (Becker (1973, 1974), Becker et al. (1977), Montgomery and Trussell (1986), Burdett and Coles (1997)). In a basic infinite horizon search model, individuals search for suitable marriage partners and receive offers drawn from some known distribution. Search continues until a partner is found whose "quality" equals or exceeds an endogenously determined reservation value. In this setup, the instantaneous exit rate to marriage depends on the probability of receiving a marriage proposal and on the probability of its acceptance. The latter is in turn a function of the reservation threshold, which is determined by parameters such as search costs, discount rate, reservation utility in single state and the probability of receiving an offer. Standard search theory predicts that, all else equal, higher

\footnotetext{
${ }^{6}$ See Lehr et al. (2006), Gillett and Lehr (1999), Crandall and Jackson (2001), Bellou (2010), Forman et al. (2012) and Greenstein and McDevitt (2009).
} 
search costs lower the reservation value and increase the probability of marriage. An increase in the offer arrival rate, however, has a theoretically ambiguous effect on the propensity to marry.

In this framework, the Internet can be viewed as a means of decreasing search frictions either by reducing the cost of search or by increasing the offer arrival rate. In an offline, decentralized environment searching for a suitable partner can be a lengthy process accompanied by uncertainty regarding match quality and psychological costs associated with personal encounters and potential rejections. An online centralized marriage market instead has the potential to resolve a number of these issues. This is because it allows for targeted search along certain desirable characteristics while the users retain a degree of anonymity. Within a short time period, a set of plausible matches can be identified, which is possibly larger than the set formed via the individual's offline social network. In this sense, the Internet creates an important margin for efficiency gains stemming from diminished costs of search. If this is true, then, all else equal, we should empirically observe a negative relationship between Internet diffusion and marriage rates. The latter, however, will be dampened to the extent that online search involves costs. These can represent membership or usage fees of online services or the time cost and effort to either use a computerized system or disentangle truly compatible types among the expanding pool of available candidates. The latter point is relevant given the degree of misrepresentation and lying that occurs with respect to individual physical appearance or marital status. ${ }^{7}$

The second plausible effect of the Internet is to increase the arrival rate of offers. Theory predicts that higher Internet penetration will affect the probability of marriage in any direction. On the one hand, greater exposure to potential mates will increase the frequency of offers and

\footnotetext{
${ }^{7}$ In a survey organized by Pew Internet (2005) more than $50 \%$ of the internet users, agreed that misinformation regarding the true marital status is an important concern. Moreover, $20 \%$ of those looking for a partner but who have never used online personals revealed that the lack of trust towards these sites is the main reason why they have not explored this venue. However, despite the fact that some stigma regarding online dating still persists, most Internet users do not view it simply as a last resort.
} 
therefore the likelihood of marriage. On the other hand, as the offer probability rises, so does the individual's reservation value. Consequently, the likelihood of accepting an offer declines as well as the probability of marriage. Hence, the net effect of an increase in the frequency of offers on marriage, spurred by Internet diffusion, remains an empirical question. ${ }^{8}$

Finally, the impact of the Internet on marriage likely varies across demographic groups as their search costs and offer arrival rates vary within their own marriage market. The potential of the Internet to affect matching is probably the greatest for those perceived as facing thinner markets or those who experience difficulties in meeting potential mates (e.g same sex couples or racial minorities). In Section 5.4, a heterogeneity analysis is performed in order to identify any differential effects on marital outcomes of selected population groups.

\section{Data and Descriptive Statistics}

\subsection{Data}

To establish a link between Internet diffusion and marriage patterns, I exploit variation in marriage rates and broadband penetration within states over time and across states. The main analysis relies on data from two sources. First, to measure marriage propensities, I use information on the current marital status of the respondents from the March CPS Supplements (years 1990-1995 and 2001-2006). The outcome of interest is whether the individual has ever been married. The baseline sample consists of approximately 180660 white (non-Hispanic) males and females aged 21-30 years old. This primary age group includes individuals who have recently been or currently are in the marriage market and so are more likely to be affected by current

\footnotetext{
${ }^{8}$ These arguments essentially imply an ambiguous effect of the Internet on divorce and remarriage. If targeted search leads to matches of more compatible people, such matches will likely be more stable. However, if meeting people becomes easier at all times and ages so that a divorce seems less costly, then this could imply entering a marriage less thoughtfully to begin with. In the latter case, we might expect higher marriage rates (related to Internet expansion) but also higher incidence of divorce. I will provide some preliminary suggestive evidence on the link between Internet diffusion and divorce in Section 5.5.
} 
marriage and labor market conditions. Hence, this outcome likely captures transitions into first marriage. Because there are important differences in the marriage patterns of whites (nonHispanics), African Americans (Shannon Seitz (2009)) and Hispanics, I choose to study the decisions of these groups separately. Therefore, I first focus on the behavior of the white nonHispanic population and in Section 5.4 I discuss heterogeneous effects for other racial groups.

Based on the above definition, Appendix Table 1 describes age-specific marriage rates across states at four points in time. In 1990 and 1995, when Internet technology and in particular broadband was virtually nonexistent, in 2001, at the very early stages of broadband, and in 2006. Clearly, marriage propensities have been falling over time, a phenomenon that was particularly prevalent in the mid-1970s and 1980s. There is, however, substantial state heterogeneity in the way marriage rates have evolved over time. While for certain states, marriage rates continued to fall rapidly (Arizona, Kentucky, Louisiana, Tennessee), in others the fall happened at the same fairly constant rate (Alabama, California, Georgia, Ohio) or even at a much slower pace (Delaware, DC, New York, Colorado). While this preliminary pass-through in the data is purely descriptive, the goal of this paper is to examine to what extent these trends are causally affected by the simultaneous growth in broadband Internet technology.

Figure 1 tracks the propensity to marry by the age of 40 for cohorts of (white) population aged 21 years old in 1980, 1985, 1990, 1995, and 2000. ${ }^{9}$ First of all, as is depicted, marriage propensities grow substantially less after the age of 30. By then, the vast majority of individuals have already been married once. Therefore, ages 21-30 is the appropriate range to focus on. Moreover, while the propensity to marry has significantly fallen at relatively younger ages, the

\footnotetext{
${ }^{9}$ This figure is constructed as follows. Consider, for instance, the cohort of 21 year olds in 1980 . This cohort will be 25 years old in 1984, 30 in 1989, 35 in 1994 and 40 in 1999. Hence, I calculate the fraction of ever married population aged (i) 21 in 1980 (ii) 25 in 1984 (iii) 30 in 1989 (iv) 35 in 1994 and (v) 40 in 1999 and then plot these five points on the graph.
} 
propensity to marry by the age of 30 and even more by the age of 40 has fluctuated much less. This is an important observation because it implies that the decay in marriage rates for this focal group mostly refers to a marriage delay rather than an overall rejection of the concept of marriage. In this sense, search theory provides an appropriate framework to address variations in the marital search decision. ${ }^{10}$

I supplement the data on marriage rates from the CPS with information on state-level broadband diffusion as well as other state covariates. The broadband market is an industry that has been growing very rapidly since the 1996 Telecommunications Act facilitated entry of more telecommunication service providers. The data on broadband penetration is obtained from the Federal Communications Commission Statistical Reports on Broadband Deployment. These reports summarize data on high-speed Internet subscribership gathered through the Form 477 that qualifying carriers are required to file twice a year. I focus on broadband adoption by households since home is the most typical point of Internet access. Information on residential broadband penetration first became available by the FCC in December 2000 and is recorded annually since then. While deployment started taking place after 1996, the FCC does not publicly report any state-specific statistics on diffusion referring to the 1996-1999 period.

I measure the evolution of home broadband diffusion during 2000-2005 by the number of residential high-speed lines per 100 people in a state. ${ }^{11}$ Since this information is only available at the state level, it naturally restricts the definition of the "local" marriage market to also be the

\footnotetext{
${ }^{10}$ See Loughran (2002) for a similar argument.

${ }^{11}$ (i) High-speed lines are defined as those that provide speeds exceeding 200 kilobits per second (kbps) in at least one direction. (ii) The FCC actually lumps together the high-speed lines for residential as well as small-business use. I have no way to distinguish between the two. (iii) Prior to June 2005, providers with fewer than 250 high-speed lines in service in a particular state were not required to report data for that state. Small providers of high-speed connections are therefore underrepresented in the earlier data. This change in the filing requirement potentially introduces some measurement error in the measure of broadband diffusion, which likely attenuates my estimates. (iv) For confidentiality purposes, the FCC does not report information on broadband deployment for Wyoming in 2000.
} 
state. Because the CPS records individual behavior in the March of each year while data on broadband adoption are collected later in December, I assume that marriage patterns in a given year are affected by the level of Internet availability recorded in the December of the previous year. For instance, under this assumption, marriage rates recorded in March 2001 are influenced by the broadband availability as measured in December 2000. This effectively means that I use the changes in the evolution of broadband between 2000 (the first year FCC makes available such data) and 2005 to explain changes in marital patterns between 2001 and 2006.

Because I only observe changes in Internet diffusion and marriages after the advent of broadband, the importance of pre-existing trends will not be adequately accounted for. For this reason, I take advantage of the fact that prior to 1996 home broadband penetration was virtually nonexistent and I supplement the 2001-2006 marriage sample with CPS years 1990-1995 and setting, hence, the number of pre-1996 residential broadband lines to zero. ${ }^{12}$ Therefore, the final sample spans the years 1990-1995 (pre-broadband era) and 2001-2006 (post-broadband era).

Appendix Table 1 summarizes the state-specific changes in this measure during the period of study. As is evident, there is significant variability in deployment within and across years and states. By 2005 there were on average about 14 lines per 100 people up from 0.9 in 2000, but across states adoption varied from 0.14 lines in 2000 in Mississippi to 3.18 lines in New Hampshire. Nevertheless, even though the speed of diffusion within the examined five-year period has been remarkable, penetration took place much more slowly in certain states (Iowa, Kentucky, S. Dakota) than in others (New Jersey, Connecticut, Maryland).

There are two main conceptual issues associated with this measure of Internet diffusion. First of all, it is a measure that captures evolution in the availability of this technology and not

\footnotetext{
${ }^{12}$ See Forman et al. (2012) for a similar strategy. The March Supplements of CPS provide annual information on the marital status of the respondents for all years since 1962.
} 
individual Internet usage per se and in particular pertaining to the focal group of interest of 21-30 year olds. While this can be perceived as limitation of the analysis, broadband diffusion remains an informative and policy-relevant parameter and is likely more exogenous than respondent's own Internet usage.

Second, broadband diffusion focuses on high-speed Internet subscribership and as such it does not directly reflect variation in dial-up usage over the period of study. The dial-up was a predominant form of Internet connection until the early 2000s but since then, its incidence leveled-off and then plummeted. According to statistics published by the NTIA (2004, 2010), there has been a dramatic crowd-out of dial-up by broadband: the number of households with high-speed or broadband connections grew from 9.9 million in September 2001 to 22.4 million in October 2003. Dial-up connections declined by $12.7 \%$ or 5.6 million households during the same period. In 2009 only 5\% of all households were using dial-up while 64\% were broadband subscribers. In addition, the decline in the share of dial-up users has been more than offset by the expansion of broadband Internet users, leading to a net increase of Internet usage from home at the extensive margin. ${ }^{13}$ The shift towards broadband reflects the fact that the latter allows faster access to a greater volume of information thus significantly improving the online experience of the users.

The crowding-out of dial-up and the advent of broadband have likely transformed the economic as well as social landscape and in particular the way people connect and communicate at all levels. Broadband is associated with more intensive use of the Internet from consumers and also with their engagement to a wider variety of online activities. This is especially true for communication activities such as emailing or sending instant messages (NTIA, 2010). The

\footnotetext{
${ }^{13}$ It is worth noting that that the broadband's rate of diffusion has outpaced that of many other popular technologies in the past such as video cassette recorders and personal computers (NTIA, 2004).
} 
pumped-up consumer demand for new virtual activities related to broadband deployment has further accelerated business innovation by introducing new consumer applications and services (ITU, 2012). While the significant crowding-out of dial-up does not necessarily imply that broadband is more effective at improving matching, it is suggestive that it may have at least facilitated and intensified the use of the Internet as an intermediary for partner search. Increasingly more people access the Web than before and can resort to online resources as a fast and possibly more efficient way of meeting others (via email, instant message, chat rooms, online dating). At the same time the number of social networking and online dating sites offering such services has been rapidly expanding. ${ }^{14}$ For these reasons, broadband penetration is potentially a more relevant measure of Internet penetration than dial-up during the period of study and even more so for younger individuals, who tend to use broadband more intensively and whose marital choices are the outcome of interest.

Finally, the analysis is supplemented with a broad set of aggregate covariates controlling for factors that could affect both broadband deployment as well as marriage decisions. I include two sets of state-level, time-varying covariates. First, to account for the fact that broadband deployment is influenced by a number of demographic and economic aspects of the "local" market, I introduce controls that capture overall economic prosperity, business activity and the demographic composition of the state. These are: population density, the fraction of the population that is nonwhite, the fraction of the population in various age groups, the state's unemployment rate, log GDP, median household income as well as the number of firms operating in high-tech sectors that are presumably more prone to adoption of advanced Internet technology (Prieger (2003); Stevenson (2007) \& (2008); Forman et al. (2012)). I further include household

${ }^{14}$ Most social networking and online dating sites such as Facebook, Google+, Classmates.com, eHarmony, Yahoo Personals were lunched in the post-broadband era, that is after 1996. 
telephone penetration as a potential proxy for the role of dial-up connection, since the latter requires a telephone line. ${ }^{15}$

In addition to these controls, I include a set of state covariates that are race and agespecific, aiming at describing relevant economic opportunities and demographic and regional factors correlated both with broadband deployment as well as marriage decisions among 21-30 year olds (Blau et al. (2000)). These covariates are: the sex ratio, defined as the number of men over the number of women in a given group, mean male and female employment rates and wages, average schooling and the fraction of people residing in a metropolitan area as a proxy for urbanicity. For the baseline model detailed in the next section, the latter set of controls represents state means calculated for 21-30 years old white individuals. When other population subgroups are discussed in Section 5.4, these controls are appropriately adjusted to reflect the characteristics (in terms of age, race and/or education) of the group of interest. Population density, urbanicity and the sex ratio are also proxies for the local marriage market conditions. Population density and urbanicity could be viewed as influencing the probability of meeting a partner, while the sex ratio the extent of local competition for age and race-eligible partners.

Appendix Table 2 provides summary statistics for the above covariates in selected sample years. Appendix Table 3 displays results from a regression of household broadband penetration during 2000-2005 on the list of state covariates mentioned above as well as state and year

${ }^{15}$ (i) An additional potential indicator of the surrounding economic environment, which can also influence the decision of marriage, is the evolution of house prices (Lehr et al. (2006)). This variable is available from the Census for only a subset of years of my baseline sample. For this reason, it is not part of the standard set of covariates used for model estimation. Controlling for this factor, however, in the subset of available sample years, essentially left the estimates unchanged. Furthermore, cellular telephony was another communication technology that began to diffuse before 1996 and which is likely complementary to broadband. This is because Internet connection can also be achieved through cell-phones. FCC reports data on mobile phone subscribership by state in the years after 1998. Restricting the sample to the 20012006 period and controlling for cell-phone adoption does not change the baseline estimates. Results are available upon request. (ii) The number of firms operating in high-tech sectors is calculated from the County Business Patterns. To define "high-tech" industries, I follow Hecker (1999). The remaining state covariates are calculated from the March Supplements of the CPS. 
dummies. Coefficients of variables that are statistically significant at conventional levels are only reported. The results suggest that population density, the age composition of the state, its level of education as well the strength of the high-tech sector are among the most important determinants of broadband expansion. As some of these determinants likely influence marriage patterns, the empirical analysis controls for all these potentially confounding factors.

\subsection{Internet Expansion and Marriage Rates: Preliminary Evidence}

Figure 2a provides a first pass through the data giving a visual cue of the source of variation employed in order to identify the impact of Internet diffusion on marriage rates. As formally explained in the next section, the latter effect is identified from variation in marriage rates and Internet penetration within states over time and across states. This strategy importantly eliminates biases due to state-specific time invariant unobservable factors correlated with the level of broadband deployment and marriage rates. Figure 2a associates changes in the share of (white) ever-married 21-30 year olds between 2001 and 2006 to the changes in broadband diffusion within states in these years, hence, netting out fixed unobservable state characteristics. This figure essentially previews my main result: marriage rates grew on average more in states with greater increases in broadband penetration.

Figure $2 \mathrm{~b}$ displays the difference in the change in marriage rates between 2001-2006 and 1995-1990 graphed against the difference in the change in broadband diffusion between 2005 2000 and 1995-1990 (essentially zero). This approach eliminates state-specific time invariant unobservable factors that are correlated with changes in marriage rates and broadband expansion. The figure suggests an even steeper positive relationship between the variables of interest once such factors are accounted for. While the preliminary evidence presented in these figures is suggestive of a potentially causal link between the two variables, the remaining of the paper seeks to more formally establish whether this is indeed the case. 


\section{Econometric Methodology}

The search model briefly outlined in Section 2 suggests that the propensity to marry in a given period depends on an exogenously determined offer arrival rate and a reservation value. The first component is a function of the local marriage market conditions influenced by, for instance, the sex ratio or the degree of local Internet availability, whereas the second component is affected by elements that include the cost of soliciting offers, the individual's discount rate, single-state reservation utility, as well as the offer arrival rate. Assuming that the latter variables are in turn functions of observable and unobservable individual characteristics, the propensity to marry can be estimated in reduced form by the following linear probability model:

$$
\text { Married }_{i s t}=\beta_{0}+\beta_{1} \text { Internet }_{s t}+\beta_{2} X_{i s t}+\beta_{3} Z_{s t}+\sum_{s} \varphi_{s}+\sum_{t} \rho_{t}+\varepsilon_{i s t}
$$

Here Married $_{\text {ist }}$ is a dichotomous variable that equals 1, if respondent $i$ residing in state $s$ in year $t$ has ever been married and 0 otherwise. The dependent variable is constructed from the current marital status variable of the March CPS. ${ }^{16}$ Vector $X_{i s t}$ contains basic demographic individual characteristics such as the respondent's education as well as whether she resides in a metropolitan area. ${ }^{17}$ To capture the impact of age on the marriage behavior I add age dummies. The addition of these terms allows interpreting the dependent variable as the propensity to marry by a given age. $Z_{s t}$ is a vector of state variables including unemployment rate, population density, and age and race-specific state covariates, such as sex ratio, wages and employment. The set of all variables forming vector $Z$ is described in Section 3.1. Internet $t_{s t}$ is the variable of interest measured by the number of residential high-speed Internet lines per 100 people in a given state and year.

\footnotetext{
16 Individuals who cohabit as unmarried partners can only be identified in the data after 1995. Approximately 5\% of the individuals report living with an unmarried partner in the period 2001-2006. I treat individuals who cohabit as singles. However, the main findings remain intact if I treat them as "married" or if I eliminate them completely from my sample.

${ }^{17}$ First, I estimate (Eq. 1) separately by gender to establish whether Internet penetration has a differential effect on the marriage behavior of men and women. In specifications where I pool data for both groups, I supplement (Eq. 1) with an additional regressor for the gender of the respondent.
} 
$\varphi_{s}$ and $\rho_{t}$ are state and year fixed effects respectively. The former capture any timeinvariant state-specific characteristics that simultaneously influence broadband deployment and marriage rates. Year fixed effects control for unobserved factors affecting the likelihood of marriage that are common to all states in a given year. Hence, the parameter of interest, $\beta_{1}$, is solely identified from within-state variation in broadband penetration and marriage over time. Cross-sectional variation does not contribute to the estimates. As long as the fixed effects do not vary over time, this approach will yield unbiased estimates of $\beta_{1}$. Finally, (Eq. 1) is estimated using the available sampling weights. The standard errors are corrected to take account of both the clustered structure of the error term as well as the fact that Internet diffusion varies at a higher level of aggregation than the individual units. To obtain heteroskedasticity-robust standard errors, I cluster them by state and year.

The estimation of (Eq. 1) using fixed effects will provide useful inference about the causal impact of Internet penetration on marriage, if Internet diffusion is truly exogenous. This assumption will not hold if, for instance, there are unobserved factors that trend over time within a state and are correlated with broadband diffusion and marriage or if states that were already experiencing increasing marriage rates were more likely to adopt the new technology. Then, the estimated effect would simply reflect a continuation of this pre-existing trend. To assess these possibilities, I supplement (Eq. 1) with state-specific linear time trends. In this case Internetrelated marriage effects are identified using within-state variation in the marriage rate (relative to the national trend) after netting-out state-specific time trends. While this is a more conservative estimation strategy, as it eliminates not only strong cross-sectional variation in the levels but also in the trends in marriage and Internet diffusion, it will importantly highlight whether omitted variable bias due to gradually evolving unobserved state characteristics is driving the main results. This strategy will also address the importance of pre-existing state-specific conditions. 
The fact that the baseline sample dates back to 1990 and includes five years prior to the advent of broadband (1990-1995) will help to more credibly identify such trends (Wolfers (2006)).

I address further potential identification concerns related to omitted-variable bias in four different ways. First, I consider models with region-year and division year-interactions in order to investigate the importance of different sources of spatial heterogeneity. These terms will sweep out between-region (division) variation and therefore estimates will be based on variation solely within each region (division) over time. Second, using the specific timing of the diffusion of broadband (largely after the 1996 Telecommunications Act), I construct a series of falsification checks aiming at testing whether broadband diffusion in the 2000s can predict marriage rates and other marriage-related outcomes in the before broadband era. Third, I investigate whether the identified effect is biased by the presence of reverse causality driven by immigration decisions of married individuals towards states with a certain level of Internet penetration. Fourth, I implement an instrumental variable strategy where Internet diffusion is instrumented with household telephone diffusion in 1955. The rationale for the instrument is based on the hypothesis that Internet diffusion may follow long-standing patterns in the adoption of other communication technologies and in particular that of the telephone. While the possibility of endogeneity cannot be completely ruled out, the results from Section 5.2 seem to overwhelmingly support the causal interpretation of the estimated effects.

\section{Results}

\subsection{Baseline Estimates}

Table 1 reports results from the estimation of specification (Eq. 1) with and without the inclusion of state-specific linear time trends. Recall that the sample spans the years 1990-1995 (prebroadband era) and 2001-2006 (post-broadband) and consists of 21-30 year old white respondents. Columns 1 and 2 present estimates using the entire sample, while Columns 3-6 
estimates of (Eq. 1) by gender. While the flows into marriage are the combined result of actions of both sides of the market, it is possible that a state variable, such as Internet penetration, has a differential effect on men and women.

The results uniformly indicate that broadband diffusion has significantly increased marriage rates among 21-30 year olds. The coefficient of interest in the pooled sample is 0.0053 and implies that that one extra broadband line per 100 people is associated with an increase in the proportion of ever-married individuals by 0.53 percentage points. When state-specific trends are allowed for, the coefficient further increases to 0.0075 . This result suggests that the relationship between Internet penetration and marriage rates is not spurious and furthermore that unobserved factors associated with rising marriage propensities have actually made states less likely to adopt the new technology. Quantitatively, the estimated effects presented in Columns 1 and 2 imply an Internet-related increase in marriage rates of approximately 0.96-1.4 percent from the 1990 level. Gender-specific marriage responses are qualitatively similar to the pooled estimates. While in the plain fixed effects model the estimates are somewhat lower for women, this discrepancy disappears once state-specific trends are introduced. This suggests that unobserved heterogeneity is likely more important for the female decision to marry. ${ }^{18}$

${ }^{18}$ (i) Given the well-documented issues of linear probability models, I have also experimented with a probit specification. The coefficient of Internet diffusion was 0.0059 with a standard error of 0.002 . (ii) $0.9 \%-1.4 \%$ result from $0.0053 / 0.548$ and $0.0075 / 0.548$ respectively, where 0.548 is the percentage of ever married white (non-Hispanic) population aged 21-30 in 1990 (iii) The unit of measurement of broadband diffusion is lines per 100 people in a state. To convert this to units of Internet usage, I proceed as follows. First, I use the 2000, 2001 and 2003 CPS Computer and Internet Supplements to construct an individual measure of home Internet usage. Then, I assign broadband penetration by state and survey year and regress Internet usage among 21-30 year old (non-Hispanic) whites on broadband diffusion, basic individual covariates, state, year fixed effects and state-specific trends. The obtained coefficient is 0.012 and statistically significant. This implies that an expansion in household broadband by 1 line per 100 people increases home Internet usage in the focal demographic group by 1.2 percentage points. (iv)The IV coefficients are also very similar for men and women (0.013 and 0.01 respectively) and strongly statistically significant. Since both sides of the market are affected by Internet diffusion in very similar ways, in the remaining of the analysis I pool the two samples together and study the combined effect. 
Appendix Table 4 displays analytically coefficient estimates of all the remaining covariates included in (Eq. 1). They overall have the expected signs. In particular, marriage decisions are significantly affected by the local marriage market conditions proxied by urbanicity and the sex ratio. A higher number of men relative to women decreases the chances than a woman remains single, while the opposite is true for men. It is the latter effect that dominates in the aggregate. Moreover, the odds of getting married are positively related to the population density of the state and to urbanicity. This result is likely due to the fact that the size of the market is an increasing function of the population of the state, while more urban areas are typically more densely populated, which would also tend to increase the meeting rate. While urbanicity is important regardless of gender, it appears that density is a stronger determinant of the marriage decision of women. Finally, the size of the age-eligible for marriage population also matters: the greater the share of younger individuals (aged 16-35 years old) in the total population, the higher the marriage rates. Regarding the significance of the local economic environment for marriage decisions, the results suggest that men tend to marry more in highincome states and when labor market prospects for females improve (as measured by female wages), while women tend to marry less in areas with more employment opportunities. Finally, areas where the high-tech economy is more developed display lower marriage rates. ${ }^{19}$

\footnotetext{
${ }^{19}$ As marriage and technology diffusion are dynamic processes, it is plausible that a given level of Internet penetration has lagged effects on the marriage response beyond the 3-month lag that is implied by the timing the two variables are measured. To study the potential presence of such effects, I first use the Akaike criterion to select the model of distributed lags with the best fit. This amounts to estimating (Eq. 1) with the contemporaneous level of Internet diffusion as well as its third and fifth lag. The estimated coefficients are respectively: 0.005 (s.e (0.0018)), -0.0013 (s.e (0.0033)) and 0.0083 (s.e (0.0062)). While the "immediate" effect remains almost identical to the coefficient estimated in Column 1 of Table 1, the lagged terms are not individually distinguishable from zero. The three coefficients are, however, jointly statistically significant. Moreover, note that the coefficient of the fifth lag is quantitatively larger than the contemporaneous estimate implying non-negligible long term effects of Internet diffusion: a marginal increase in Internet penetration in a given year will, all else constant, increase marriage rates by 0.8 percentage points five years later. Taking into account the lagged effects, over a five-year period, a unit increase in Internet diffusion has a cumulative impact on marriage rates of 1.2 percentage points. This
} 


\subsection{Identification of a Causal Relationship}

The identifying assumption of the empirical strategy is that, conditional on all covariates, the diffusion of broadband Internet is exogenous. This assumption can be violated due to the presence of unobserved heterogeneity that is not adequately controlled for by the inclusion of time-varying state covariates, state and year fixed effects as well as state-specific linear time trends. In this section, I further assess the validity of the exogeneity assumption by performing a series of tests. The latter will enhance our understanding as to whether a causal interpretation can be attached to the baseline estimates.

To start with, in Columns 1 through 4 of Table 2, I explore a different source of identification that relies on variation in marriage rates and Internet diffusion within regions and census divisions. In Columns 1 and 2, I introduce interactions between the four census regions and the year fixed effects and with and without allowing respectively state-specific linear time trends. In Columns 3 and 4, I instead consider interactions between the period fixed effects and the nine census divisions. These spatial interactions are a flexible way of accounting for changes in underlying regional or division-level factors that trend arbitrarily over time. As can be seen, the estimates survive these stringent tests even when state trends are introduced, hence providing support in favor of the robustness of the baseline effects established in Table $1 .{ }^{20}$

Another source of bias could be due to reverse causality induced by the moving decisions of more marriage-oriented people towards states with a certain level of Internet penetration. To investigate this issue, I use the limited information in the March CPS on the migration status of the respondent in the past year in order to define a moving dummy for whether the individual

\footnotetext{
suggests an increase in marriage propensity by roughly 2.5 percent from an overall mean of 0.484 during the entire period of study $(0.012 / 0.484)$.

${ }^{20}$ I have also experimented with models including up to a quartic state-specific time trend and with and without allowing for region-year interactions. The results are qualitatively robust and within the range of estimates displayed in Table 2.
} 
switched states since last year. When this term is included in the baseline specifications in Columns 5 and 6 (Table 2), the coefficient of interest is only negligibly affected. Cross-state migration instead, has an individually significant effect on marriage propensities. ${ }^{21}$

In the second half of Table 2, I use the particular timing in the advent of broadband to perform a series of falsification tests for the validity of the exogeneity assumption. Broadband Internet's wide diffusion was primarily realized in the years after 1995. As a result, logic suggests that there should not be any association between future adoption and marriage propensities prior to 1995. If a systematic relationship is detected, then this indicates that the exogeneity of broadband deployment is likely violated.

To implement this falsification strategy, I collapse the data in state-year averages and study how changes in broadband diffusion between 2000 and 2005 affect changes in marriage propensities in the years immediately preceding broadband (1990-1995). ${ }^{22}$ In Column 1 , I regress the change in marriage propensities between 1990-1995 on the change in broadband diffusion between 2000-2005 as well as changes in the remaining covariates over the same period. The estimate suggests that future penetration cannot predict past marriage patterns. In Columns 2-5, I repeat the same experiment using 1990-1995 changes for a different set of dependent variables that are, however, highly correlated with marriage: fertility, measured by the propensity to have a child in the population of 21-30 year olds, the share of 21-30 year olds that have obtained college education, the propensity of 25-35 year olds to divorce and finally the state's sex ratio referring to

\footnotetext{
${ }^{21}$ As information on the state of residence in the previous year is not reported in 1995, conditioning on cross-state migration results in a small sample size reduction.

${ }^{22}$ I have repeated this falsification test defining as “no-adoption” period the years 1985-1991. I have also experimented with other narrower temporal windows. I did not find any systematic relationship between future diffusion and past outcomes in any of these cases. This falsification strategy is similar to Forman et al. (2012).
} 
21-30 year old whites. ${ }^{23}$ In all cases, future adoption has no predictive power on the outcomes measured before advanced telecommunications emerged. These results provide further supportive evidence of the exogeneity condition.

\subsubsection{Instrumental Variables Analysis}

Finally, as an additional check, I supplement my main findings with the results from an IV specification. To construct my instrument, I consider the hypothesis that Internet diffusion may follow long-standing patterns in the adoption of other communication technologies by households and in particular that of the telephone. ${ }^{24}$ To test this hypothesis, I study the relationship between modern broadband diffusion and residential telephone adoption in $1955 .{ }^{25}$

In Appendix Figure 1a, I plot state broadband diffusion in 2005 against that predicted by telephone ownership in 1955. The figure unsurprisingly displays a strong predictive power of these historical patterns of telephone adoption and lends support to the null that Internet penetration resembles the historical adoption of similar types of innovations. Furthermore, this strong relationship is not exclusive to 2005 but extends to all sample years.

The fact that the diffusion of the telephone several decades ago can predict contemporaneous Internet diffusion implies that there are certain state-specific characteristics that drive overall technological penetration, which are relatively stable over time. These characteristics could reflect land/housing features, basic infrastructure or attitudes and cultural

\footnotetext{
${ }^{23}$ I focus on the age group of 25-35 year olds when studying divorce response, because this is when first divorces likely take place. This specification also serves as a useful falsification check for the results presented in Section 5.5 concerning the impact of Internet adoption on other marital outcomes.

${ }^{24}$ See Stevenson (2006) for a similar argument.

${ }^{25}$ Residential telephone adoption is measured by the number of residential phones per family in a given state in 1955. I obtain information on the number of residential telephones in 1955 and the number of families from the 1956 County and City Databook. In 1955, there were approximately 0.97 residential telephones per family. State adoption rates, however, varied from 0.40 (Mississippi) to 1.21 (New Jersey). No information is recorded for Alaska, which implies a small reduction in sample size when the IV specification is implemented.
} 
preferences for innovation. ${ }^{26}$ While it is not unlikely that these determinants are also correlated with marriage, the fact that they have been stable over time indicates that any underlying endogenous relationship should be captured by the presence of state fixed effects already included in the baseline model. In other words, if openness to innovation and social liberalism have steadily shaped technological change and family formation in certain states over time, then these bias-inducing unobserved factors should be accounted for by the inclusion of state fixed effects precisely because of their stable nature.

The first and second stage results are presented at the bottom panel of Table 2. Notice that because telephone adoption in 1955 is time invariant while contemporaneous Internet adoption is not, the instrument is interacted with year fixed effects to allow for time variation. Year fixed effects are still included in the model as separate covariates. The first stage estimates suggest that telephone adoption in 1955 is a significant predictor of current Internet diffusion, as already indicated by Appendix Figure 1a. Moreover, the value of the F-statistic implies that the instrument is strong, while the Hansen $\mathrm{J}$ statistic further indicates that it is independent of the error process. Turning to the second stage, the IV estimate is significant and in line with the OLS effects presented in Tables 1 and 2, although quantitatively larger: a marginal increase in the level of broadband adoption results in an increase in marriage propensities by 1.2 percentage points. ${ }^{27}$ Overall, the IV results in combination with the specifications and falsification tests

\footnotetext{
${ }^{26}$ In Appendix Figures 1b and 1c, I graph state broadband diffusion in 2005 against that predicted by the share of farm households in 1930 and the share of households in 1960 having hot and/or cold piped water (proxy for the presence of basic infrastructure). As expected, the states that adopted advanced telecommunication technologies in recent years are indeed those that had better infrastructure and a smaller share of the population residing in farms. The fact that such characteristics in 1930 and 1960 predict contemporaneous Internet diffusion provides further suggestive evidence in favor of the stability of these factors as determinants of technological diffusion over the course of the last 40 years.

${ }^{27}$ (i) The IV estimates are robust to the exclusion of years 1990-1995 and to the inclusion of regional trends. I have also experimented with the share of farm households by state in 1930 and the share of households in a state having piped water in 1960 as alternative instruments (see Appendix Figures 1b and
} 
presented in Table 2 are suggestive of a causal relationship between Internet diffusion and marriage rates. ${ }^{28}$

\subsection{Interpretation of the baseline effects}

How can we interpret the results presented in Tables 1 and 2 and what do they imply about the trajectory of marriage rates post-1990? To evaluate the magnitude of the estimated effects, I will use as a lower bound of the impact of Internet expansion the baseline estimate of 0.0053 (Table 1, Column 1) and as an upper bound the IV estimate of 0.012 (Table 2). These coefficients indicate an increase in marriage rates by 0.53 - 1.2 percentage points when broadband exists. This is approximately a $0.9 \%-2.2 \%$ increase from the 1990 level. Since broadband penetration increased from 0 to 14 lines per 100 people between 1990/1995 and December 2005, extrapolating the measured coefficient to current (2006) circumstances implies that marriage rates are currently higher by roughly $13.5 \%$ - 30.6\% from what they might have been if this technology did not exist. ${ }^{29}$

Alternatively, consider another potential thought experiment. The share of ever married white individuals aged 21-30 years old was 0.734 in 1974 and 0.548 in 1990 . This means that during this 16-year period marriage rates fell by 18.6 percentage points. Now, assume that

1c). They are both strong predictors of household broadband adoption and produce very similar effects to baseline instrument. (ii) The fact that the IV estimate is larger than the OLS is consistent with the presence of measurement error in the baseline regressions. Measurement error is a possibility since prior to 2005, the number of actual high-speed lines was likely underreported given that smaller providers were not required to report to the FCC (see footnote 11).

${ }^{28}$ One possible way to test the exclusion restriction of the instrument is to check whether telephone penetration in 1955 directly predicts marital patterns prior to the advent of broadband. Under the identifying assumption, the instrument should have no predictable power. Indeed, regressing marriage rates prior to broadband (1985-1995) on the instrument (interacted with year fixed effects) as well as state and year dummies, I find no significant effect between the two quantities.

${ }^{29}$ (i) This is $0.0053 * 14 / 0.548$ and $0.012 * 14 / 0.548$ respectively. (ii) In light of the calculations explained in footnote 18, an increase in residential broadband penetration by 14 lines per 100 people translates to a sizeable increase in home Internet usage by 17 percentage points. As people use broadband to access the Internet from other locations (such as at work), this is likely only a lower bound of the overall increase in Internet usage induced by broadband. 
nothing else (other than Internet diffusion) changes in the subsequent post-1990 years (relative to the 1974-1990 period) and that marriage rates continue to fall by the same absolute amount between 1990 and 2006. This would imply that the 2006 marriage rate among 21-30 year olds should have been 0.362 . The data, however, indicate that the actual share of ever married individuals in this age group is 0.412 . That is, the current level is $13.8 \%$ higher relative to the theoretically predicted level of 0.362 . Hence, under the strong assumption that the same conditions prevail between 1990-2006 as they did between 1974-1990, these back-of-theenvelope calculations suggest that Internet diffusion could entirely account for the observed rise in marriage rates.

\subsection{Heterogeneity Analysis}

The analysis presented so far indicates that Internet diffusion has played an important role in transforming one of the aspects of the marriage market, namely the transition into first marriage. The results from a number of tests suggest that this relationship is also causal. However, it is unlikely that the effect has been uniform across the entire population. As the costs and benefits of search vary across demographic groups along with their opportunities to access the Internet, we might observe broadband diffusion having a more pronounced effect on the marital outcome of certain groups versus others. In Table 3 I explore such possibilities. ${ }^{30}$

In Columns 1 and $2 \mathrm{I}$ assess whether Internet diffusion has similarly altered the marital decisions of younger (aged 16-20) and older (aged 31-35) groups relative to the core population of 21-30 year olds. The results suggest that there is a significant impact on the marriage response of younger individuals. A marginal increase in Internet expansion is associated with an increase in marriage propensities of $16-20$ year olds by $0.5-1.8$ percentage points. This corresponds to a roughly $8 \%-27 \%$ increase in marriage rates in this group from the 1990 average (0.065). There is

\footnotetext{
${ }^{30}$ Table 3 shows OLS and IV estimates in order to provide a low and an upper bound of the effect.
} 
no discernible effect among relatively older individuals. This is not surprising since the majority of respondents in this group, and especially women, have already been married at least once by the age of 30 .

Columns 3 and 4 present results by education group. While the Internet has affected the search behavior of both groups in a similar manner, the IV estimate suggests that the marriage behavior of the more educated is weakly more responsive to Internet expansion. This could reflect that the latter may have had more exposure to computers and online browsing and therefore can better familiarize themselves and use various online services more effectively. Subsequently, in Columns 5 and 6, I ask whether populations in urban areas profit more from greater Internet access than populations residing outside of the central city. The effect in this case could theoretically go either way. In urban areas, the Internet is more accessible but potentially more expensive. There are also more opportunities to meet people offline. However, because the set of options expands, it may take longer to locate the most appropriate match. On the other hand, in less urban areas, deployment has been slower but Internet access possibly more affordable, while the pool of potential partners is relatively limited. The results suggest that all individuals have similarly responded to Internet diffusion regardless of their location status. ${ }^{31}$

In Columns 7 \& 8 I explore whether marriage responses of other racial groups resemble that of whites. If some of these populations perceive themselves as facing thinner marriage markets and Internet helps to alleviate this concern, then expanding adoption may substantially

\footnotetext{
${ }^{31}$ (i) The differential effect by education group in the IV specification is statistically significant at the $10 \%$ level. The differential effect in the OLS model is insignificant. (ii) The March CPS does not formally distinguish between urban and less urban areas. Hence, I define an area as "urban" on the basis of the metropolitan status of the respondent. I categorize the individual as residing in an urban area if he/she reports living in the central city of an MSA. If instead a broader definition is chosen whereby "urban" reflects whether an individual resides in a metro area, then the results clearly indicate that the baseline effects are driven by respondents living in MSAs.
} 
improve matching efficiency for these groups. I find that Internet availability has contributed to increased marriage rates among (non-Hispanic) Blacks but not among Hispanics. While the IV estimate for the latter group is sizeable, it is statistically insignificant. The effect on the black population is quantitatively similar to the effect on the white marriage rates. The presence of broadband is associated with an increase in black marriage rates by $0.45-1.6$ percentage points, which amounts to a $1.2 \%-4.2 \%$ increase from the 1990 level (0.377). This result is consistent with evidence presented by Stevenson and Wolfers (2007) using Forrester data that Blacks are more likely to use online personals than whites. Using the 2005 Pew Internet and American Life Project Survey, I also find that, conditional on being an Internet user, 22\% of 21-30 years old, non-Hispanic Blacks use online dating services as opposed to $15 \%$ for non-Hispanic whites in the same age group (and this difference is statistically significant). This is a feature that pertains to other survey years as well and is also reflective of the fact that, while racial digital divide still persists, the share of African Americans that are Internet users increased dramatically between 2000 and 2011 compared to other racial groups. ${ }^{32}$

\subsection{Other outcomes}

If the Internet has successfully affected transitions into first marriage, a natural question is whether it has also shaped other marital outcomes such as remarriage and divorce. CPS only reports the current marital status of the respondent and therefore does not distinguish between the first and subsequent marriages. This means that I cannot explicitly relate Internet diffusion to remarriage or ever-divorced rates. For this reason, I compute another potentially informative statistic: whether individuals aged 25-35 and 36-55 years old respectively are currently married

\footnotetext{
${ }^{32}$ The share of Black (non-Hispanic) adults using the Internet increased from 35\% in June 2000 to $71 \%$ in August 2011, which is a more than $100 \%$ increase. For whites (non-Hispanic) the change was relatively more moderate climbing from $49 \%$ to $80 \%$ within the same period. For Hispanics, Internet usage increased from 40 to 68\%. (Pew Internet \& American Life Project Report (2012)).
} 
as opposed to divorced or separated. This variable is meant to capture the propensity to be “matched” at all times conditional on ever been married. I would expect a positive relationship between Internet diffusion and these quantities, if the Internet (i) either allows individuals to establish more suitable and therefore lengthier first matches or (ii) facilitates post-breakup marital search. Case (ii) is associated with higher propensity to enter faster another formal relationship given separation.

Table 3 displays the results. The estimates suggest that greater Internet adoption has not only induced more marriages among 21-30 year olds but has also increased the propensity of individuals to generally be in formal relationships conditional on marriage. This is true for both age groups. Future research, relying on more suitable data, should shed some light on whether this result reflects lengthier first marriages and/or faster remarriage. ${ }^{33}$

\section{Discussion}

The key result of the empirical analysis is that Internet technology has contributed to more marriages in recent years. The objective of this section is to elaborate on the potential channels through which such a transformation has taken place. In particular, two relevant mechanisms are discussed. First, how people use the Internet to look for a partner and second, whether online methods have crowded-out more traditional forms of search. The answer to these questions is seriously complicated by the lack of relevant information in the large publicly available datasets. For that matter, since the CPS Supplements do not provide any such information, I turn to a number of alternative sources.

33 (i) The median time from first marriage to separation is approximately 7 years and therefore most transitions from first marriage to divorce likely take place in the age range of 25-35 years old (Census, May 2011). (ii) These results are robust to correction for the non-random selection of individuals in the divorced sample using a "Heckman selection-correction". 
Regarding the usage of online resources for partner search, the September 2005 survey released by the Pew Internet and American Life Project as well as Dutton et al. (2008) provide some preliminary information on the ways respondents employ the Internet to meet people. According to Dutton (2008), 49\% of the romantically linked couples that were surveyed met through an online dating website, $13 \%$ through chat rooms, $12 \%$ via instant messaging and another $12 \%$ via social networking websites. Also, other ways were reported such as emailing or browsing for information about the local singles scene. It is interesting to note that among the couples who reported having met online, more than $50 \%$ responded that they have done so via a way other than a dating website. Hence, it is important to emphasize that, even though dating through organized matchmaking websites seems to be an easy and to efficient way of meeting people (Hitsch et al. (2010)), individuals appear to be using online resources in a much broader way when looking for a partner. Having said this, the baseline estimates presented in Tables 1-3 can, therefore, be interpreted the overall effect of direct and indirect ways the Internet is utilized to look for a partner, from online dating to searching online for offline singles events.

I provide more rigorous evidence on the link between online dating usage and marriage using related information from the Pew Internet surveys. ${ }^{34}$ A question on the usage of online dating sites for partner search was asked during the 2000 and 2002-2006 surveys. This information was organized in state-year averages and merged with the baseline CPS sample. Table 4 Columns 1 and 2 present results from estimation of (Eq. 1) using state-level online dating usage as the covariate of interest in lieu of Internet adoption. The estimate suggests that, conditional on state and year fixed effects as well as state-specific linear time trends, growing

\footnotetext{
34 These are nationally representative surveys. In each of the years a sample was collected of approximately 3000 people. Across surveys, information only on online dating usage was consistently collected. Hence, no firm conclusion about the effectiveness of other forms of internet search can be drawn. Individuals also reported information on their state of residence.
} 
utilization of online dating services is associated with higher marriage propensities. In particular, an increase in usage by 1 percentage point implies a statistically significant increase in marriage propensity by 7.8 percentage points. This suggests an increase in the share of ever married 21-30 year olds by roughly 17 percent relative to the mean. ${ }^{35}$

The above estimate implies that this new form of social intermediation has been effective at improving matching efficiency. Has it displaced or complemented, however, other more traditional forms of search? Preliminary descriptive evidence supportive of a crowding-out effect is offered by Rosenfeld and Thomas (2012). Using information on how a sample of romantically linked individuals first met, they show that some of the most traditional ways of meeting partners experienced significant declines post-1995. These include meeting through friends, co-workers, family, school, the neighborhood and church. The Internet instead gained unambiguously in importance and in particular among homosexual couples. While these conclusions are drawn from plain data tabulations, the mere fact that nearly all offline forms of meeting have been in decline during the Internet era suggests that the Internet might have played a displacing rather than complementary role in the social arena.

I provide further statistical evidence in line with the above finding using time-use data on the socializing habits of single young Americans aged 21-30 years old. This information is obtained from the ATUS and covers the period 2003-2006. I construct two outcome variables of interest: the amount of leisure time (in minutes) an individual spent socializing with others

\footnotetext{
${ }^{35}$ The specification is estimated using CPS data for the years 2000, 2002-2006 for which corresponding information on online dating usage (from Pew Internet) exists. The model includes the standard covariates employed in all reported specifications. The sample consists of white individuals aged 21-30 years old. The estimate is also robust to the inclusion of region-year interactions. The average (ever) marriage rate among 21-30 year olds between 2000-2006 is 0.449. (ii) A model with quadratic state-specific trends produces an even larger effect and also statistically significant. While the possibility of endogeneity of online-dating usage cannot be ruled out, the robustness of the estimate to the addition of state-specific trends somewhat alleviates concerns related to omitted variable bias.
} 
(friends, parents, co-workers, neighbors) and the amount of individual leisure time spent on using the computer without the presence of others. While the ATUS does not elaborate on the precise activities the individual performed with a computer, the overall time allocated on this activity likely includes time spent on using online dating sites, social networking sites, emailing and chatting. ${ }^{36}$ If Internet diffusion has indeed displaced traditional offline forms of search in favor of online alternatives, then we might also expect a decrease in the amount of time spent socializing with others likely accompanied by an increase in the time spent alone using a computer. In other words, if personal interaction (with friends, family, neighbors) declines in the Internet era, then the likelihood of meeting potential partners through ones' offline social network may also diminish.

In Columns 1 and 2 of Table 4 I present results from the estimation of (Eq. 1) where the outcome variables are the amount of leisure time spent socializing with others and the amount of alone time spent on using a computer for non-work related purposes. The model is estimated using individual-level ATUS data for the survey years 2003-2006 on a sample of single (never married) respondents aged 21-30 years old. The estimates indicate that Internet availability is associated with significantly less time spent on interacting with others, which may imply a declining propensity to meet potential partners through traditional offline ways. On the other hand, time spent alone using a computer for leisure has significantly increased as a result of greater Internet availability. These effects do not only offer indirect support to the hypothesis that

\footnotetext{
${ }^{36}$ I focus on the 2003-2006 period because these are the years for which data exists on both time use as well as Internet diffusion. ATUS first started to collect time use information in 2003. Non-work time spent socializing includes socializing, communicating, playing games, doing arts and crafts, listening to music, watching movies, attending social events with other people (parents, siblings, friends, coworkers, neighbors). Non-work time spent using the computer includes time spent checking household and personal emails and messages as well as time spent on computer use for leisure (browsing on the Internet, participating in chat rooms burning CDs, downloading files, pictures and music but excluding playing games).
} 
the Internet has likely reshaped the venues through which relationships are formed but also signify that this technology has profound and seemingly negative implications for social capital accumulation among young people and in particular of the type formed outside the household. ${ }^{37}$

\section{Conclusion}

The Internet's potential to change matching has been studied in the context of the labor and housing markets. The goal of this paper is to explore the impact of this technology on matching efficiency in the marriage market and in particular on the transition into first marriage. From a theoretical perspective, the Internet can be viewed as a mechanism that may reduce search frictions by increasing, for instance, the arrival rate of offers. Since theory in this case predicts an ambiguous effect on the probability of marriage, it is ultimately an empirical question to determine the direction of the effect. To my knowledge, this is the first paper to empirically undertake this task.

To plausibly identify this effect, I exploit temporal and geographic variation in the diffusion of broadband Internet among households, which rapidly began to take place since the 1996 Telecommunications Act. I find that Internet expansion is associated with increased marriage rates in the benchmark population of 21-30 year old whites. Similar effects are identified for younger individuals in the same racial group as well as for African Americans. While the available data do not allow determining which online search methods are effective, suggestive evidence is offered that Internet has crowded out other traditional methods of meeting potential partners and that online dating services contribute to increased marriage rates.

\footnotetext{
${ }^{37}$ The specifications also control for the day of the week the survey took place. The estimates remain qualitatively robust to the inclusion of state-specific linear time trends. However, as the sample size is fairly small, the addition of these terms significantly increases standard errors. Furthermore, the results are similar if the analysis includes the entire population of 21-30 year olds and not just singles (never married). Results for time spent socializing are robust to extending the outcome variable to include other social capital building activities such as volunteering or church attendance.
} 
While the analysis strongly suggests that Internet is a powerful technology with real effects on family formation, the quality of the matches formed through the Internet remains an open question. Although match quality may improve as the Internet allows for the selection of mates with desired characteristics, the easiness and the speed of meeting new divorcees makes divorce an attractive option while increasing the likelihood of remarriage. In this context, I show that Internet availability improves the chances of being matched at all times (conditional on ever getting married) as opposed to be separated or divorced. However, I cannot disentangle whether this is due to the Internet leading to more stable matches or due to facilitating remarriage. Future research on this topic relying on better data will need to separately address these possibilities.

\section{References}

Bailey, Martha J. (2006): “More Power to the Pill: The Impact of Contraceptive Freedom on Women’s Life Cycle Labor Supply,” Quarterly Journal of Economics, Vol. 121(1), pp. 289-320.

Bellou, Andriana (2010): "Internet Access and the Black and White Gap in Youth Unemployment: Evidence from the Broadband Market,” Working Paper, University of Montreal.

Becker, Gary. (1973): “A Theory of Marriage I,” Journal of Political Economy, Vol. 81(4), pp. 813-846. Becker, Gary. (1974): “A Theory of Marriage II,” Journal of Political Economy, Vol. 82(2), pp. S11-S26. Becker, Gary, Landes, Elisabeth and Robert Michael. (1977): “An Economic Analysis of Marital Instability,” Journal of Political Economy, Vol. 85(6), pp. 1141-1187.

Blackburn, McKinley, David Bloom, and David Neumark (1993): “Fertility Timing, Wages, and Human Capital,” Journal of Population Economics, Vol. 6(1), pp. 1-30

Blau, Franchine D., Lawrence M. Kahn and Jane Waldfogel (2000): “Understanding Young Women’s Marriage Decisions: The Role of Labor and Marriage Market Conditions,” Industrial and Labor Relations Review, Vol. 53(4), pp. 624-647. 
Brown, Jeffrey R. and Austan Goolsbee (2002): “Does the Internet Make Markets More Competitive? Evidence from the Life Insurance Industry,” Journal of Political Economy, Vol. 110(3), pp. 481-507. Burdett, Kenneth, and Melvyn G. Coles. (1997): “Marriage and Class,” Quarterly Journal of Economics, Vol. 112(1), pp. 141-68.

Crandall, Robert and Charles Jackson (2001): “The \$500 Billion Opportunity: The Potential Economic Benefit of Widespread Diffusion of Broadband Internet Access,” mimeo, Criterion Economics, Washington, DC, July

Dahl, Gordon. (2010): “Early Teen Marriage and Future Poverty,” Demography, Vol. 47(1), pp. 689-718. Dutton, William H., Ellen J. Helsper, Monica T. Whitty, Galen Buckwalter and Erina Lee (2008): “Mate Selection in the Network Society: The Role of the Internet in Reconfiguring Marriages in Australia, the United Kingdom and United States,” Working Paper.

Forman, Chris, Avi Goldfarb and Shane Greenstein (2012): “The Internet and Local Wages: A Puzzle,” American Economic Review, Vol. 102(1), pp. 556-75

Fountain, Christine (2005): “Finding a Job in the Internet Age,” Social Forces, Vol. 83( 3, pp. 1235-1262. Gillett, Sharon E. and William H. Lehr (1999): “Availability of Broadband Internet Access: Empirical Evidence,” paper presented to the Twenty-Seventh Annual Telecommunications Policy Research Conference, September 25-27, 1999, Alexandria, VA.

Goldin, Claudia and Lawrence F. Katz (2002): “The Power of the Pill: Oral Contraceptives and Women’s Career and Marriage Decisions,” Journal of Political Economy, Vol. 110(4), pp. 730-770.

Goolsbee, Austan and Jonathan Guryan (2006): “The Impact of Internet Subsidies in Public Schools,” Review of Economics and Statistics, Vol. 88(2), pp. 336-347.

Greenstein, Shane and Ryan C. McDevitt (2009): “The Broadband Bonus: Accounting for Broadband Internet’s Impact on U.S GDP,” NBER Working Paper No. 14758

Hadass, Yael S. (2004): “The Effect of Recruiting on the Matching of Workers and Employers,” mimeo, Harvard University 
Hecker, Daniel (1999): “High-technology Employment: a Broader View,” Monthly Labor Review, pp. 1828.

Hitsch, Gunter J., Ali Hortaçsu, and Dan Ariely (2010): "Matching and Sorting in Online Dating," American Economic Review, Vol. 100(1), pp. 130-163.

ITU Report (2012): “The Impact of Broadband on the Economy: Research to Date and Policy Issues”

Klepinger, Daniel , Shelly Lundberg.\& Robert Plotnick (1995): “Adolescent Fertility and the Educational Attainment of Young Women,” Family Planning Perspectives, Vol. 27(1), pp. 23-28.

Kuhn, Peter and Skuterund, Mikal (2004): “Internet Job Search and Unemployment Durations,” American Economic Review, Vol. 94(1), pp.218-232

Lehr, William H., Carlos A. Osorio, Sharon E. Gillett, and Marvin A. Sirbu (2006): "Measuring Broadband’s Economic Impact,” Working Paper

Liebowitz, Stan J. and Alejandro Zentner (2012): “Clash of the Titans: Does Internet Use Reduce Television Viewing,” Review of Economics and Statistics, Vol. 94(1), pp. 234-245

Loughran, David S.(2002): “The Effect of Male Wage Inequality on Female Age at First Marriage,” Review of Economics and Statistics, Vol. 84(2), pp. 237-251.

Loughran, David S and Julie Zissimopoulos (2009): "Why Wait? The Effect of Marriage and Childbearing on theWages of Men andWomen,” The Journal of Human Resources, Vol. 44(2), pp. 326-349.

Montgomery, M. and J. Trussell (1986): “Models of Marital Status and Childbearing,” in Ashenfelter, O. and R. Layard (eds.), Hanbook of Labor Economics, Vol. II, (North- Holland, Amsterdam) NTIA report (2004): “A Nation Online: Entering the Broadband Age,” U.S. Department of Commerce, Economics and Statistics Administration

NTIA report (2010): “Exploring the Digital Nation: Home Broadband Internet Adoption in the United States,” U.S. Department of Commerce, Economics and Statistics Administration

Pope, Devin and Kory Kroft (2012): "Does Online Search Crowd Out Traditional Search and Improve Matching Efficiency? Evidence from Craigslist”, Journal of Labor Economics, forthcoming 
Prieger, James E. (2003): “The Supply Side of the Digital Divide: Is There Equal Availability in the Broadband Internet Access Market?,” Economic Inquiry, Vol. 41(2), pp. 346-363.

Rosenfeld, Michael and Reuben Thomas (2012): "Searching for a Mate: The Rise of the Internet as a Social Intermediary,” American Sociological Review, Vol. 77(4), pp. 523-547.

Seitz, Shannon (2009): “Accounting for Racial Differences in Marriage and Employment,” Journal of Labor Economics, Vol. 27(3), pp. 385-437.

Stevenson, Betsey (2006): “The Impact of the Internet on Worker Flows,” Working Paper, The Wharton School, University of Pennsylvania

Stevenson, Betsey and Justin Wolfers (2007): “Marriage and Divorce: Changes and their Driving Forces,” Journal of Economic Perspectives, Vol. 21(2), pp. 27-52.

Stevenson, Betsey (2009): “The Internet and Job Search,” NBER Chapters in: Studies of Labor Market Intermediation, University of Chicago Press, pp. 67-86

Wolfers, Justin (2006) “Did Unilateral Divorce Laws Raise Divorce Rates? A Reconciliation and New Results,” American Economic Review, Vol. 96(5), pp. 1802-1820.

Zickuhr Kathryn and Aaron Smith (2012): “Digital Differences”, Pew Internet and the American Life Project 

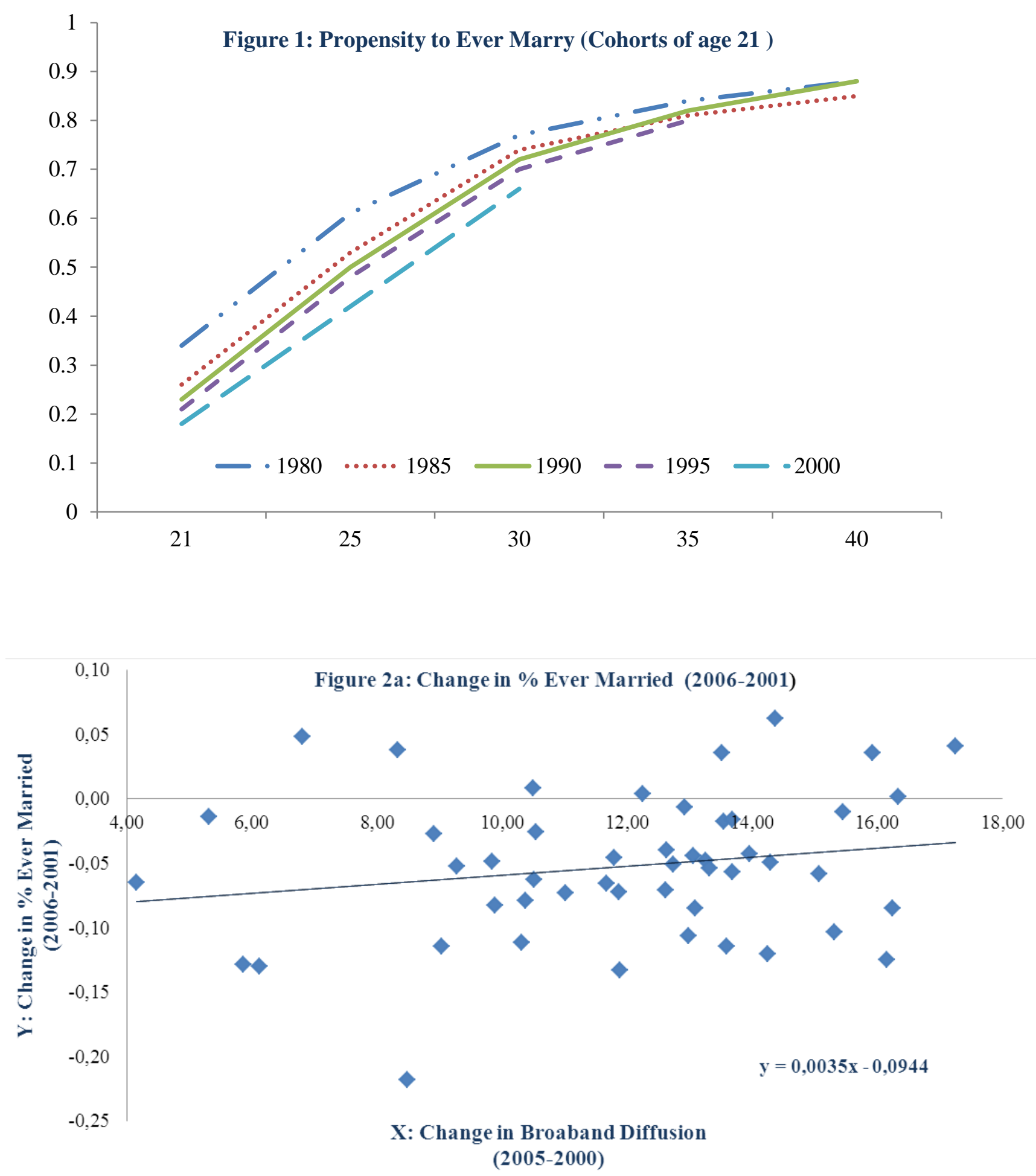


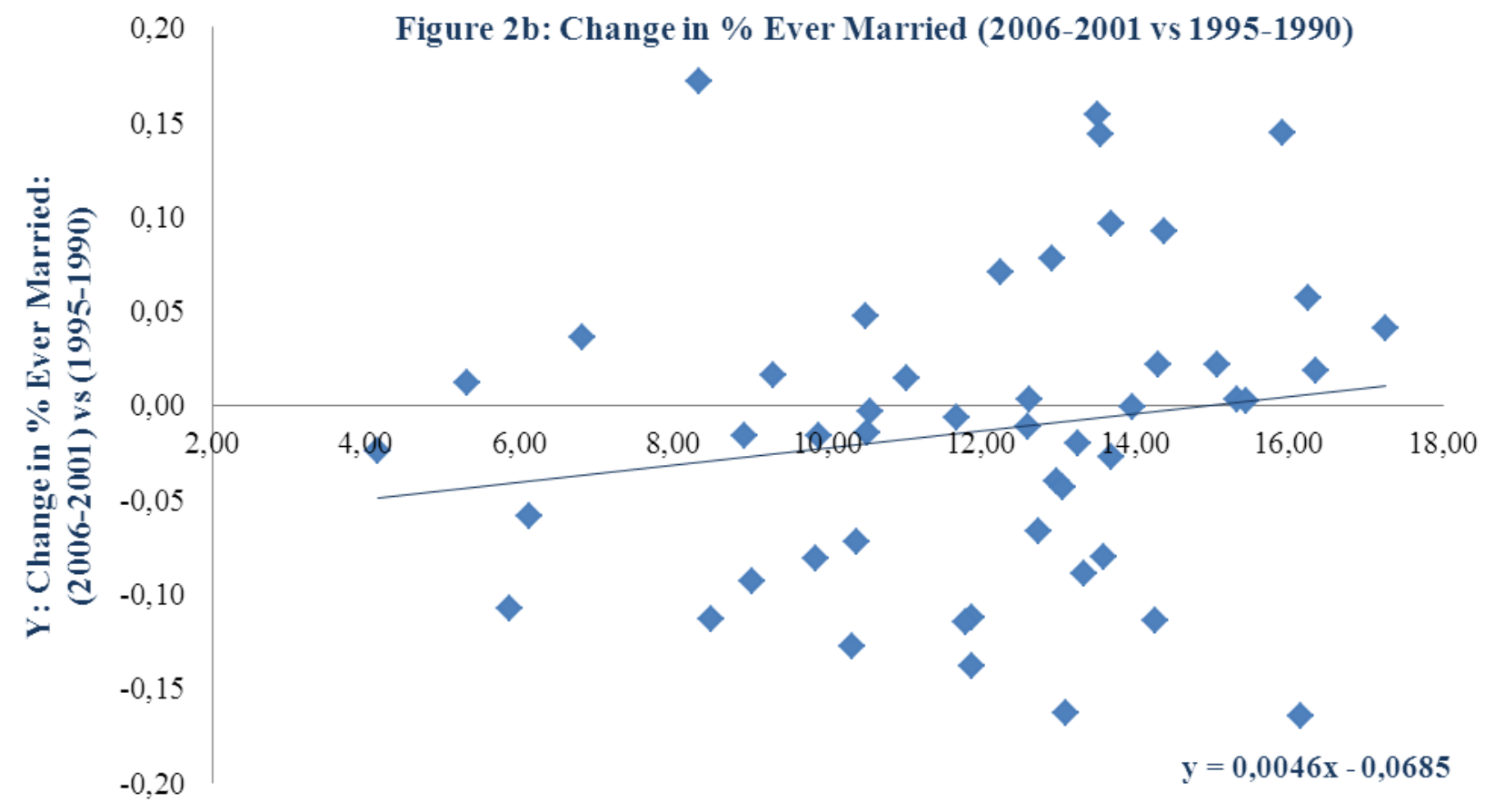

$\mathrm{X}$ : Change in Broaband Diffusion (2005-2000) vs (1995-1990)

Table 1: Impact of Broadband Diffusion on Marriage Rates (Baseline)

\begin{tabular}{|c|c|c|c|c|c|c|}
\hline DV: Ever Married & (1) & (2) & (3) & (4) & (5) & (6) \\
\hline [Mean] & $\underline{\underline{\text { All }}}$ & All & $\frac{\underline{\text { Men }}}{[0.408]}$ & Men & $\underline{\underline{\text { Women }}}$ & Women \\
\hline Internet diffusion & $\begin{array}{c}0.0053 \\
(0.0016)^{* * *}\end{array}$ & $\begin{array}{c}0.0075 \\
(0.0022)^{* * *}\end{array}$ & $\begin{array}{c}0.0074 \\
(0.0015)^{* * *}\end{array}$ & $\begin{array}{c}0.0076 \\
(0.0024)^{* * *}\end{array}$ & $\begin{array}{c}0.003 \\
(0.002)\end{array}$ & $\begin{array}{c}0.0074 \\
(0.0028)^{* * *}\end{array}$ \\
\hline $\begin{array}{l}\text { State \& Year dummies } \\
\text { State-specific linear time } \\
\text { trend }\end{array}$ & Yes & Yes & Yes & Yes & Yes & Yes \\
\hline Observations & 180660 & 180660 & 86606 & 86606 & 93854 & 93854 \\
\hline
\end{tabular}

See text for variable definition. Robust standard errors (parentheses) are clustered at the state-year level.

$* * *$ denotes statistical significance at $1 \%$. 
Table 2: Impact of Broadband Diffusion on Marriage Rates (Robustness)

\begin{tabular}{|c|c|c|c|c|c|c|}
\hline DV: Ever Married & $(1)$ & $(2)$ & (3) & $(4)$ & $(5)$ & (6) \\
\hline Internet diffusion & \multirow{4}{*}{$\begin{array}{c}0.0052 \\
(0.0016)^{* * * *}\end{array}$} & \multirow{4}{*}{$\begin{array}{c}0.0061 \\
(0.0022)^{* * *}\end{array}$} & \multirow{4}{*}{$\begin{array}{c}0.0039 \\
(0.0018)^{* *}\end{array}$} & \multirow{4}{*}{$\begin{array}{c}0.0039 \\
(0.0022)^{*}\end{array}$} & 0.0045 & 0.0071 \\
\hline & & & & & $(0.0016) * * *$ & $(0.0023)^{* * *}$ \\
\hline "Move" dummy & & & & & 0.023 & 0.023 \\
\hline & & & & & $(0.007) * * *$ & $(0.007) * * *$ \\
\hline State \& year dummies & Yes & Yes & Yes & Yes & Yes & Yes \\
\hline $\begin{array}{l}\text { State-specific linear time } \\
\text { trend }\end{array}$ & No & Yes & No & Yes & $\mathrm{No}$ & Yes \\
\hline Region-year interactions & Yes & Yes & No & No & No & No \\
\hline Division-year interactions & No & No & Yes & Yes & No & No \\
\hline Observations & 180660 & 180660 & 180660 & 180660 & 167147 & 165807 \\
\hline
\end{tabular}

Falsification Tests

DV: Change (1990-1995)

in: $\quad \%$ Ever \% Divorced \% Ever have \% College Sex ratio married (25-35yrs old) had a child education (21-30 yrs old)

\begin{tabular}{lccccc}
\hline Change Internet diffusion & 0.0013 & -0.0041 & 0.0021 & 0.002 & 0.0127 \\
$(2000-2005)$ & $(0.0053)$ & $(0.0046)$ & $(0.0055)$ & $(0.0058)$ & $(0.0129)$
\end{tabular}

$\begin{array}{llllll}\text { Observations } & 44 & 44 & 44 & 44 & 44\end{array}$

\section{IV: Number of residential phones per 100 families in a state}

Second Stage - DV: Ever Married

Internet Diffusion

IV

0.012

$(0.0028)^{* * *}$

First Stage - DV: Number of high-speed lines per 100 people in state

phones 1955*year2001

phones 1955*year2002

phones 1955*year2003

State \& year dummies

F-stat

Hansen J statistic

Chi-sq p-value

Observations

$$
\begin{gathered}
0.021 \\
(0.006)^{* * *} \\
0.029 \\
(0.004)^{* * *} \\
0.03 \\
(0.007)^{* * *}
\end{gathered}
$$
$(0.004)^{* * *}$ phones 1955*year2004

0.05 $(0.006)^{* * *}$ phones $1955 *$ year2005

0.06 $(0.008)^{* * *}$ phones 1955*year2006 0.082 $(0.011)^{* * *}$

See text for variable definition. Robust standard errors (parentheses) are clustered at the state-year level. $* * *, * *, *$ denote statistical significance at $1 \%, 5 \%$ and $10 \%$ respectively. 
Table 3: Broadband Diffusion and Marriage Rates (Heterogeneity Analysis)

DV: Ever

Married

(1)

(2)

(5)

(6)

(7)

(8)

(9)

(10)

\begin{tabular}{|c|c|c|c|c|c|c|c|c|}
\hline & $\begin{array}{c}16-20 \\
\text { years old }\end{array}$ & $\begin{array}{c}\text { 31-35 } \\
\text { years old }\end{array}$ & $\begin{array}{l}\text { College } \\
\text { education }\end{array}$ & $\begin{array}{l}\text { Less than } \\
\text { college }\end{array}$ & $\begin{array}{c}\text { Central } \\
\text { City }\end{array}$ & $\begin{array}{c}\text { Not in } \\
\text { Central City }\end{array}$ & $\begin{array}{c}\text { African } \\
\text { Americans }\end{array}$ & Hispanics \\
\hline $\begin{array}{l}\text { Internet } \\
\text { Diffusion }\end{array}$ & $\begin{array}{c}0.0055 \\
(0.0008)^{* * *}\end{array}$ & $\begin{array}{l}-0.0021 \\
(0.0015)\end{array}$ & $\begin{array}{c}0.057 \\
(0.0028) * *\end{array}$ & $\begin{array}{c}0.0045 \\
(0.0016)^{* * *}\end{array}$ & $\begin{array}{c}0.0062 \\
(0.0034) *\end{array}$ & $\begin{array}{c}0.0049 \\
(0.0018)^{* * *}\end{array}$ & $\begin{array}{c}0.0045 \\
(0.0024) *\end{array}$ & $\begin{array}{c}0.0015 \\
(0.0028)\end{array}$ \\
\hline Observations & 101703 & 113910 & 43635 & 137025 & 36007 & 144653 & 31128 & 55555 \\
\hline $\begin{array}{l}\text { Internet } \\
\text { Diffusion }\end{array}$ & $\begin{array}{c}0.0075 \\
(0.0018)^{* * *}\end{array}$ & $\begin{array}{c}0.0029 \\
(0.0025) \\
282\end{array}$ & $\begin{array}{c}0.018 \\
(0.0053)^{* * *} \\
\end{array}$ & $\begin{array}{c}0.008 \\
(0.003)^{* * *} \\
2258\end{array}$ & $\begin{array}{c}0.015 \\
(0.0064)^{* * *} \\
004\end{array}$ & $\begin{array}{c}0.011 \\
(0.003)^{* * *} \\
1857\end{array}$ & $\begin{array}{c}0.016 \\
(0.0042)^{* * *} \\
355\end{array}$ & $\begin{array}{c}0.0049 \\
(0.0051) \\
1916\end{array}$ \\
\hline Observations & 100153 & 112084 & 43145 & 134650 & 34623 & 143172 & 30911 & $\begin{array}{l}19.16 \\
55272\end{array}$ \\
\hline State \& year effects & Yes & Yes & Yes & Yes & Yes & Yes & Yes & Yes \\
\hline $\begin{array}{c}D V: \text { Married vs divorcec } \\
\text { (or separated) }\end{array}$ & $\underline{\mathrm{OLS}}$ & $\frac{25-35 \text { years }}{\text { old }}$ & $\underline{\text { IV }}$ & & $\underline{\underline{O L S}}$ & $\frac{\text { 36-55 years }}{\text { old }}$ & $\begin{array}{c}- \\
\text { IV } \\
\end{array}$ & \\
\hline $\begin{array}{l}\text { Internet } \\
\text { diffusion }\end{array}$ & $\begin{array}{c}0.002 \\
(0.001)^{* *}\end{array}$ & & $\begin{array}{c}0.009 \\
(0.0021)^{* * *}\end{array}$ & & $\begin{array}{c}0.0013 \\
(0.0007)\end{array}$ & & $\begin{array}{c}0.007 \\
(0.0018)^{* * *}\end{array}$ & \\
\hline State \& year effects & Yes & & Yes & & Yes & & Yes & \\
\hline F-statistic & -- & & 25.4 & & -- & & 26.27 & \\
\hline Hansen-J & -- & & 3.636 & & -- & & 3.935 & \\
\hline (p-value) & -- & & 0.6030 & & -- & & 0.5587 & \\
\hline Observations & 168049 & & 165269 & & 399377 & & 393129 & \\
\hline
\end{tabular}

See text for variable definition. Robust standard errors (parentheses) are clustered at the state-year level.

***. **. * denote statistical significance at $1 \% .5 \%$ and $10 \%$ respectively. 
Table 4: Broadband Diffusion, Online Dating and Time Use

\begin{tabular}{|c|c|c|}
\hline DV: Ever Married & $(1)$ & $(2)$ \\
\hline \multirow[t]{2}{*}{ Online dating } & 0.061 & 0.078 \\
\hline & $(0.038)$ & $(0.039)^{* *}$ \\
\hline Observations & 111102 & 111102 \\
\hline State and year fixed effects & Yes & Yes \\
\hline State-specific linear time trends & No & Yes \\
\hline \multirow{2}{*}{$\begin{array}{c}\text { DV: Leisure time spent socializing with others } \\
\text { [Mean] }\end{array}$} & $(1)$ & (2) \\
\hline & [109.86] & [109.86] \\
\hline \multirow[t]{2}{*}{ Internet diffusion } & -10.52 & -12.62 \\
\hline & $(4.44)^{* *}$ & $(4.44)^{* * *}$ \\
\hline Observations & 3785 & 3785 \\
\hline \multirow{2}{*}{$\begin{array}{c}D V: \text { Leisure time spent on using the computer } \\
\text { [Mean] }\end{array}$} & $(1)$ & $(2)$ \\
\hline & [8.58] & [8.58] \\
\hline \multirow{2}{*}{ Internet diffusion } & 1.67 & 1.77 \\
\hline & $(0.83)^{* *}$ & $(0.87)^{* *}$ \\
\hline Observations & 3785 & 3785 \\
\hline State and year fixed effects & Yes & Yes \\
\hline Region-year interactions & No & Yes \\
\hline
\end{tabular}

See text for variable definition. Robust standard errors (parentheses) are clustered at the state-year level. $* * *, * *, *$ denote statistical significance at $1 \%, 5 \%$ and $10 \%$ respectively. 
Appendix Table 1: Trends in Marriage Rates and Broadband Diffiusion

\begin{tabular}{|c|c|c|c|c|c|c|c|c|c|c|}
\hline \multirow[b]{2}{*}{ State } & \multicolumn{3}{|c|}{$\%$ Ever Married } & \multicolumn{3}{|c|}{ Broadband } & \multicolumn{3}{|c|}{ Change: $\%$ Married } & \multirow{2}{*}{\begin{tabular}{|c|} 
Change: Broadband \\
$2000-2005$ \\
\end{tabular}} \\
\hline & 1990 & 1995 & 2001 & 2006 & 2000 & 2005 & $1990-1995$ & $1995-2001$ & 2001-2006 & \\
\hline Alabama & 0,68 & 0,62 & 0,57 & 0,52 & 0,73 & 10,02 & $-0,07$ & $-0,04$ & $-0,05$ & 9,29 \\
\hline Alaska & 0,63 & 0,59 & 0,58 & 0,46 & 0,09 & 13,69 & $-0,03$ & $-0,02$ & $-0,11$ & 13,60 \\
\hline Arizona & 0,48 & 0,52 & 0,48 & 0,41 & 2,73 & 14,61 & 0,04 & $-0,04$ & $-0,07$ & 11,88 \\
\hline Arkansas & 0,68 & 0,66 & 0,70 & 0,59 & 0,98 & 10,00 & $-0,02$ & 0,04 & $-0,11$ & 9,03 \\
\hline California & 0,48 & 0,44 & 0,39 & 0,35 & 3,08 & 17,05 & $-0,04$ & $-0,04$ & $-0,04$ & 13,96 \\
\hline Colorado & 0,60 & 0,44 & 0,40 & 0,39 & 2,08 & 15,63 & $-0,16$ & $-0,03$ & $-0,02$ & 13,55 \\
\hline Connecticut & 0,39 & 0,39 & 0,28 & 0,32 & 3,00 & 20,26 & 0,00 & $-0,11$ & 0,04 & 17,26 \\
\hline Delaware & 0,53 & 0,41 & 0,43 & 0,46 & 0,31 & 13,83 & $-0,12$ & 0,02 & 0,04 & 13,52 \\
\hline $\mathrm{DC}$ & 0,25 & 0,14 & 0,21 & 0,25 & 2,54 & 18,46 & $-0,11$ & 0,07 & 0,04 & 15,92 \\
\hline Florida & 0,60 & 0,49 & 0,50 & 0,40 & 1,58 & 16,90 & $-0,11$ & 0,01 & $-0,10$ & 15,32 \\
\hline Georgia & 0,61 & 0,59 & 0,57 & 0,53 & 0,83 & 14,09 & $-0,03$ & $-0,01$ & $-0,05$ & 13,26 \\
\hline Idaho & 0,64 & 0,63 & 0,64 & 0,61 & 1,02 & 9,94 & $-0,01$ & 0,01 & $-0,03$ & 8,92 \\
\hline Illinois & 0,51 & 0,45 & 0,42 & 0,35 & 1,48 & 13,15 & $-0,06$ & $-0,04$ & $-0,07$ & 11,67 \\
\hline Indiana & 0,62 & 0,58 & 0,47 & 0,47 & 0,38 & 10,87 & $-0,04$ & $-0,11$ & 0,01 & 10,49 \\
\hline Iowa & 0,56 & 0,52 & 0,53 & 0,47 & 1,89 & 6,04 & $-0,04$ & 0,02 & $-0,07$ & 4,15 \\
\hline Kansas & 0,61 & 0,54 & 0,51 & 0,41 & 2,38 & 15,37 & $-0,07$ & $-0,03$ & $-0,11$ & 12,99 \\
\hline Kentucky & 0,68 & 0,66 & 0,54 & 0,41 & 0,31 & 6,17 & $-0,02$ & $-0,12$ & $-0,13$ & 5,86 \\
\hline Louisiana & 0,66 & 0,55 & 0,65 & 0,43 & 0,90 & 9,38 & $-0,10$ & 0,10 & $-0,22$ & 8,48 \\
\hline Maine & 0,50 & 0,50 & 0,43 & 0,39 & 1,96 & 15,03 & 0,00 & $-0,07$ & $-0,04$ & 13,07 \\
\hline Maryland & 0,55 & 0,41 & 0,44 & 0,35 & 0,71 & 16,96 & $-0,14$ & 0,03 & $-0,08$ & 16,25 \\
\hline Massachusetts & 0,36 & 0,34 & 0,26 & 0,25 & 4,02 & 19,46 & $-0,01$ & $-0,09$ & $-0,01$ & 15,45 \\
\hline Michigan & 0,54 & 0,48 & 0,46 & 0,38 & 1,21 & 13,82 & $-0,06$ & $-0,02$ & $-0,07$ & 12,61 \\
\hline Minnesota & 0,45 & 0,46 & 0,47 & 0,34 & 2,10 & 13,98 & 0,01 & 0,02 & $-0,13$ & 11,88 \\
\hline Mis sissippi & 0,71 & 0,64 & 0,71 & 0,58 & 0,14 & 6,27 & $-0,07$ & 0,07 & $-0,13$ & 6,12 \\
\hline Mis souri & 0,63 & 0,59 & 0,49 & 0,43 & 1,42 & 11,93 & $-0,05$ & $-0,09$ & $-0,06$ & 10,52 \\
\hline Montana & 0,59 & 0,52 & 0,45 & 0,37 & 0,72 & 10,62 & $-0,07$ & $-0,07$ & $-0,08$ & 9,89 \\
\hline Nebraska & 0,59 & 0,52 & 0,49 & 0,49 & 2,97 & 15,23 & $-0,07$ & $-0,04$ & 0,00 & 12,26 \\
\hline Nevada & 0,60 & 0,53 & 0,53 & 0,48 & 2,51 & 16,81 & $-0,07$ & 0,00 & $-0,05$ & 14,30 \\
\hline N. Hampshire & 0,53 & 0,57 & 0,44 & 0,31 & 3,18 & 19,33 & 0,04 & $-0,13$ & $-0,13$ & 16,15 \\
\hline N. Jersey & 0,40 & 0,38 & 0,33 & 0,33 & 2,85 & 19,19 & $-0,02$ & $-0,05$ & 0,00 & 16,34 \\
\hline N. Mexico & 0,60 & 0,47 & 0,43 & 0,47 & 1,17 & 9,51 & $-0,13$ & $-0,04$ & 0,04 & 8,34 \\
\hline N. York & 0,48 & 0,37 & 0,33 & 0,32 & 2,57 & 16,25 & $-0,11$ & $-0,04$ & $-0,02$ & 13,68 \\
\hline N. Carolina & 0,57 & 0,60 & 0,57 & 0,52 & 1,03 & 14,35 & 0,04 & $-0,03$ & $-0,05$ & 13,33 \\
\hline N. Dakota & 0,53 & 0,54 & 0,39 & 0,44 & 0,90 & 7,71 & 0,01 & $-0,14$ & 0,05 & 6,81 \\
\hline Ohio & 0,56 & 0,52 & 0,47 & 0,43 & 1,54 & 14,17 & $-0,04$ & $-0,05$ & $-0,04$ & 12,63 \\
\hline Oklahoma & 0,62 & 0,69 & 0,56 & 0,52 & 1,25 & 13,05 & 0,07 & $-0,12$ & $-0,05$ & 11,80 \\
\hline Oregon & 0,59 & 0,58 & 0,48 & 0,35 & 1,93 & 16,19 & $-0,01$ & $-0,11$ & $-0,12$ & 14,25 \\
\hline Pennsylvania & 0,57 & 0,49 & 0,35 & 0,35 & 0,86 & 13,78 & $-0,08$ & $-0,14$ & $-0,01$ & 12,92 \\
\hline Rhode Island & 0,45 & 0,37 & 0,33 & 0,27 & 2,76 & 17,83 & $-0,08$ & $-0,04$ & $-0,06$ & 15,07 \\
\hline S. Carolina & 0,66 & 0,64 & 0,51 & 0,48 & 0,92 & 11,47 & $-0,02$ & $-0,13$ & $-0,03$ & 10,55 \\
\hline S. Dakota & 0,53 & 0,51 & 0,46 & 0,45 & 1,44 & 6,75 & $-0,03$ & $-0,04$ & $-0,01$ & 5,31 \\
\hline Tennessee & 0,67 & 0,69 & 0,58 & 0,47 & 1,35 & 11,67 & 0,02 & $-0,11$ & $-0,11$ & 10,32 \\
\hline Texas & 0,62 & 0,54 & 0,54 & 0,47 & 2,01 & 13,03 & $-0,09$ & 0,01 & $-0,07$ & 11,02 \\
\hline Utah & 0,67 & 0,70 & 0,66 & 0,61 & 1,34 & 11,18 & 0,03 & $-0,04$ & $-0,05$ & 9,85 \\
\hline Vermont & 0,43 & 0,51 & 0,36 & 0,27 & 1,16 & 14,25 & 0,08 & $-0,15$ & $-0,09$ & 13,09 \\
\hline V irginia & 0,55 & 0,52 & 0,42 & 0,48 & 1,14 & 15,51 & $-0,03$ & $-0,10$ & 0,06 & 14,37 \\
\hline Washington & 0,53 & 0,50 & 0,45 & 0,40 & 2,83 & 16,52 & $-0,03$ & $-0,05$ & $-0,06$ & 13,69 \\
\hline West V irginia & 0,61 & 0,60 & 0,54 & 0,46 & 0,30 & 10,68 & $-0,01$ & $-0,07$ & $-0,08$ & 10,38 \\
\hline Wisconsin & 0,48 & 0,50 & 0,41 & 0,36 & 1,08 & 13,43 & 0,02 & $-0,09$ & $-0,05$ & 12,74 \\
\hline Wyoming & 0,70 & 0,70 & 0,55 & 0,48 & $\mathrm{NA}$ & 12,24 & 0,00 & $-0,15$ & $-0,07$ & $\mathrm{NA}$ \\
\hline \multicolumn{11}{|c|}{ Broadband is measured by the number of residential high speed lines per 100 people in a state (FCC). Marriage rates } \\
\hline & & & & & & & $\therefore \quad c 0$ & 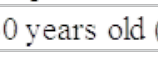 & 更 & inc) whites (CP \\
\hline
\end{tabular}


Appendix Table 1: Trends in Marriage Rates and Broadband Diffusion - Cont.

\begin{tabular}{|l|c|c|c|c|c|c|c|c|c|c|c|}
\hline \hline West Virginia & 0,61 & 0,60 & 0,54 & 0,46 & 0,30 & 10,68 & $-0,01$ & $-0,07$ & $-0,08$ & 10,38 \\
\hline Wisconsin & 0,48 & 0,50 & 0,41 & 0,36 & 1,08 & 13,83 & 0,02 & $-0,09$ & $-0,05$ & 12,74 \\
\hline Wyoming & 0,70 & 0,70 & 0,55 & 0,48 & NA & 12,24 & 0,00 & $-0,15$ & $-0,07$ & NA \\
\hline
\end{tabular}

Broadband is measured by the number of residential high speed lines per 100 people in a state (FCC). Marriage rates are calculated as the share of ever married individuals in the population of 21-30 years old (non-Hispaninc) whites (CPS).

\begin{tabular}{|l|c|c|c|}
\hline Appendix Table 2: Summary Statistics of Selected Variables & & \\
\hline \hline Variables & $\mathbf{1 9 9 0}$ & $\mathbf{2 0 0 1}$ & $\mathbf{2 0 0 6}$ \\
\hline \hline Sex ratio (21-30 yrs old) & 0.998 & 0.984 & 1.00 \\
\hline \% college education (21-30 yrs old) & 0.228 & 0.283 & 0.272 \\
\hline Mean male weekly logwages (21-30 yrs old) & 5.822 & 5.924 & 5.853 \\
\hline Mean female weekly logwages (21-30 yrs old) & 5.602 & 5.759 & 5.699 \\
\hline Fraction of females working (21-30 yrs old) & 0.952 & 0.963 & 0.953 \\
\hline Fraction of males working (21-30 yrs old) & 0.936 & 0.943 & 0.939 \\
\hline Fraction residing in an MSA (21-30 yrs old) & 0.793 & 0.803 & 0.83 \\
\hline Fraction 16-25 years old & 0.227 & 0.212 & 0.214 \\
\hline Fraction 26-35 years old & 0.273 & 0.217 & 0.205 \\
\hline Fraction 36-45 years old & 0.226 & 0.246 & 0.224 \\
\hline Fraction 46-55 years old & 0.154 & 0.205 & 0.216 \\
\hline Fraction 56 years old and above & 0.12 & 0.12 & 0.141 \\
\hline Fraction nonwhite & 0.154 & 0.183 & 0.196 \\
\hline Unemployment Rate & 0.056 & 0.047 & 0.051 \\
\hline Log Population & 14.9 & 15.012 & 15.079 \\
\hline Median Income & 14265.72 & 17210.09 & 16619.61 \\
\hline Log GDP & 11.41 & 11.71 & 11.91 \\
\hline Average number of firm in hightech sectors & 68.31 & 79.56 & 126.94 \\
\hline Age-specific stais
\end{tabular}

Age-specific statistics are calculated for the baseline sample of 21-30 years old non-Hispanic whites. GDP is obtained from the Bureau of Economic Analysis. The number of firms in hightech industries are calculated from the County Business Patterns. Population is obtained from the Census. The remaining covariates are calculated calculated from the March CPS Supplements. 


\section{Appendix Table 3: Broadband Determinants}

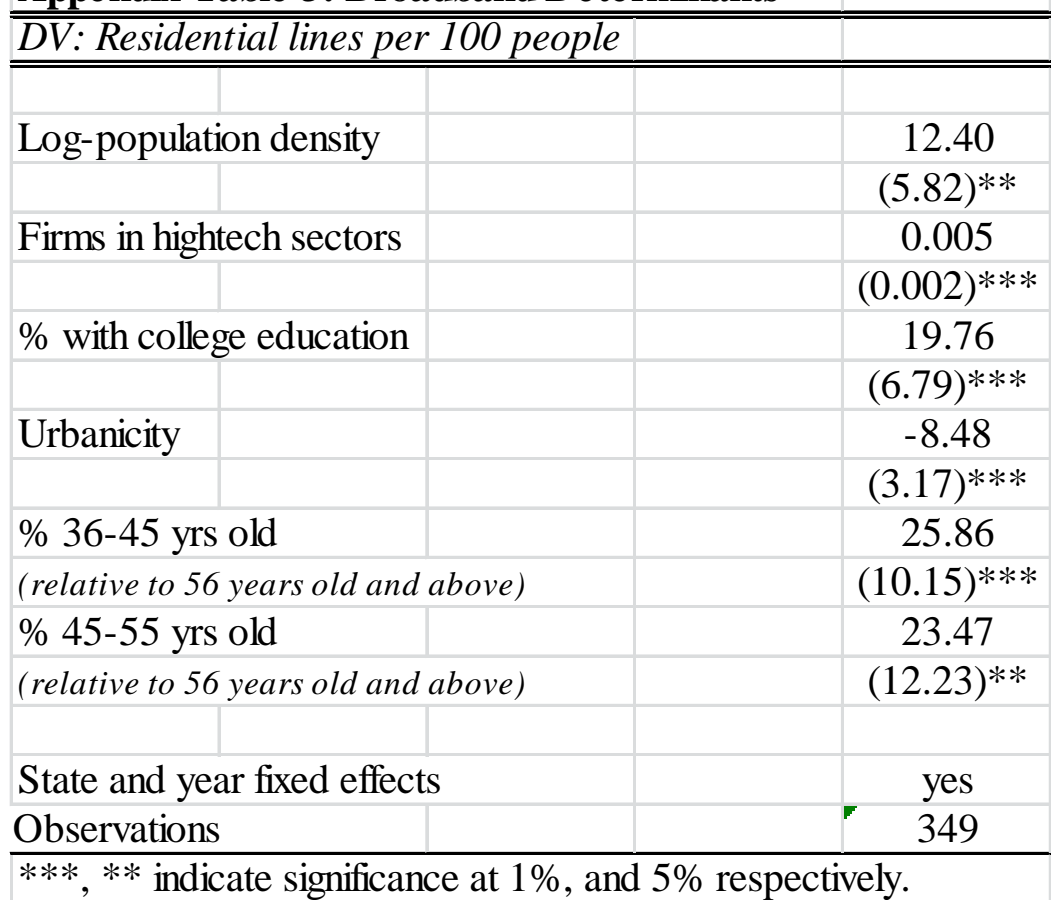




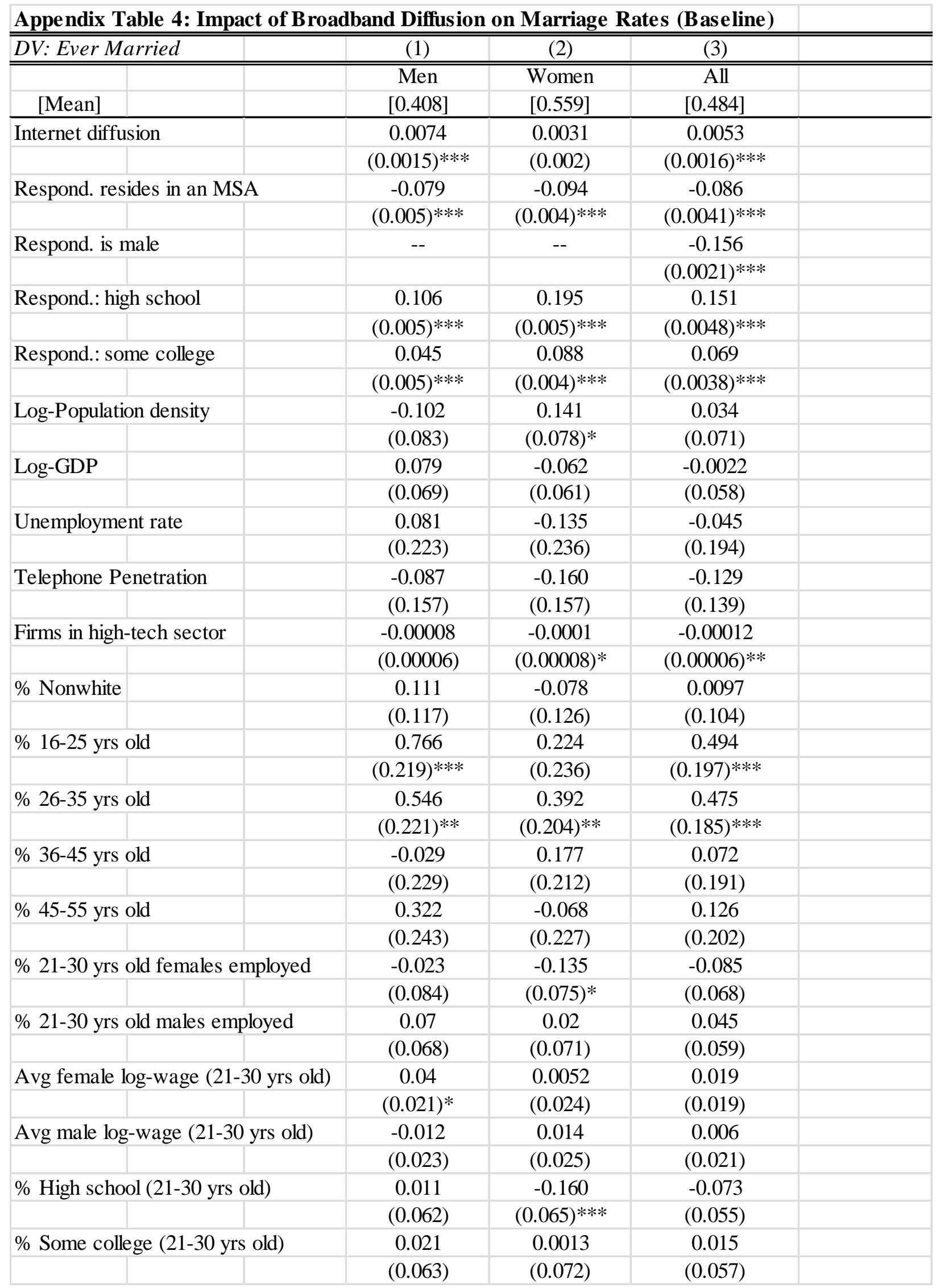




\begin{tabular}{|l|c|c|c|}
\hline \multicolumn{5}{|c|}{ Appendix Table 4: Impact of Broadband Diffusion on Marriage Rates (Base line) - Cont. } \\
\hline \hline & & & \\
\hline$\%$ 21-30 yrs old residing in MSA & 0.107 & 0.074 & 0.093 \\
\hline Sex ratio (21-30 yrs old) & $(0.047)^{* * *}$ & $(0.037)^{* *}$ & $(0.034)^{* * *}$ \\
\hline & -0.142 & 0.052 & -0.043 \\
\hline Log Household income & $(0.017)^{* * *}$ & $(0.017)^{* * *}$ & $(0.015)^{* * *}$ \\
\hline Age,State \& Year dummies & 0.065 & 0.028 & 0.045 \\
\hline State-specific linear time trend & $(0.039)^{*}$ & $(0.044)$ & $(0.036)$ \\
\hline Observations & Yes & Yes & Yes \\
\hline See text for varable & No & No & No \\
\hline
\end{tabular}

See text for variable definition. Robust standard errors (parentheses) are clustered at the state-year level. ***, $* *, *$ denote statistical significance at $1 \%, 5 \%$ and $10 \%$ respectively.

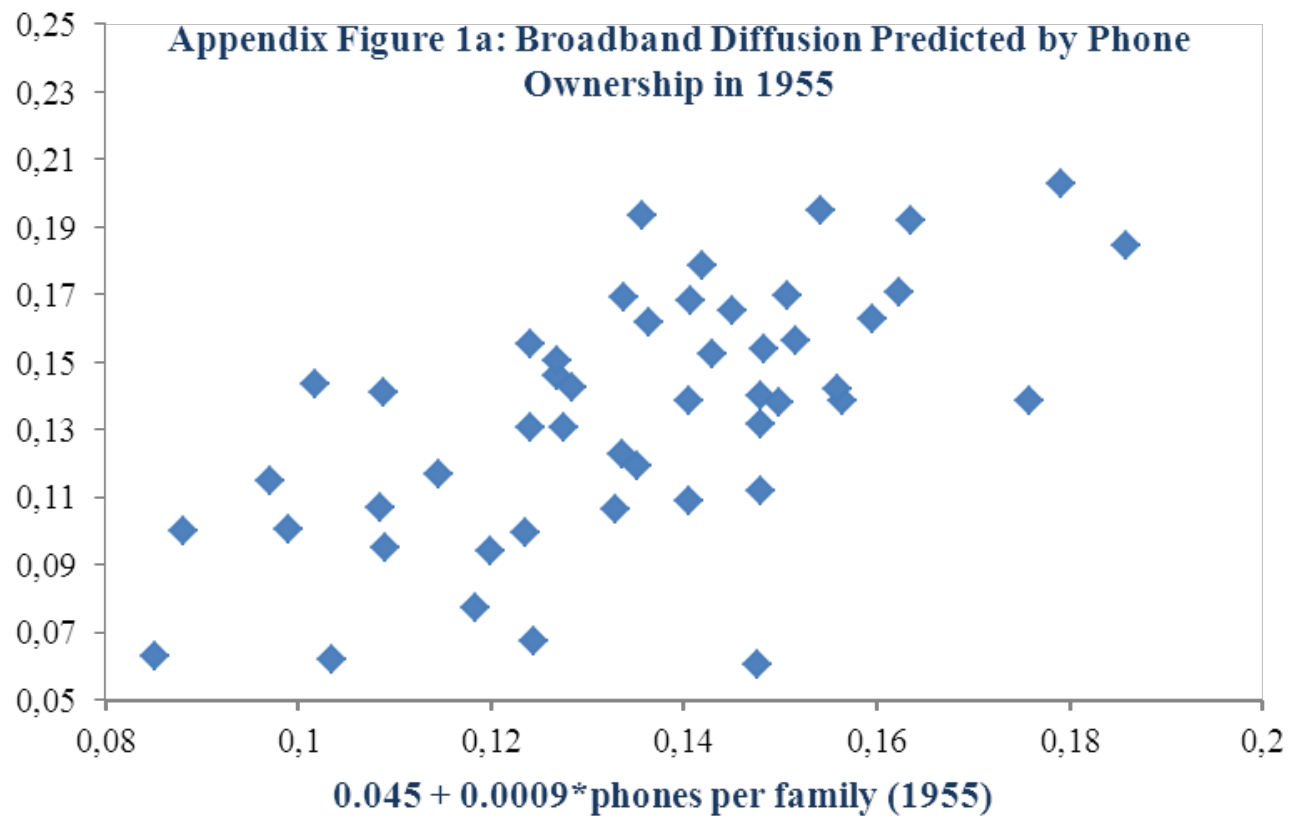



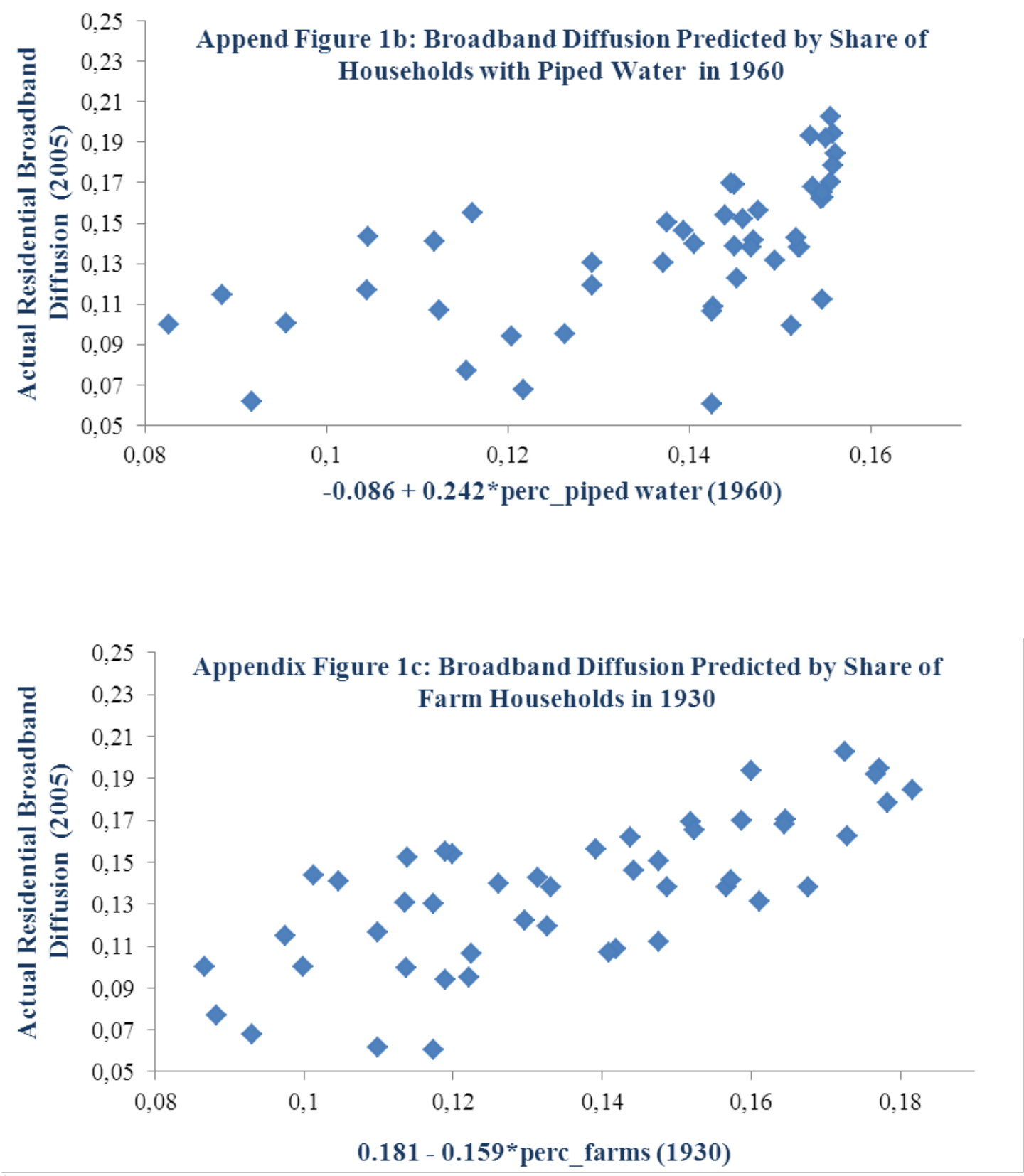